\title{
Short-term stochastic movements of electricity prices and long-term investments in power generating technologies
}

\section{Carlo Mari ${ }^{1}$}

Received: 12 August 2019 / Accepted: 23 December 2020 / Published online: 28 January 2021

(C) The Author(s) 2021

\begin{abstract}
Modeling probability distributions for the long-term dynamics of electricity prices is of key importance to value long-term investments under uncertainty in the power sector, such as investments in new generating technologies. Starting from accurate modeling of the short-term behavior of electricity prices, we derive long-term stationary probability distributions. Then, investments in new baseload generating technologies, namely gas, coal and nuclear power, are discussed. In order to compute the stochastic Net Present Value of investments in new generating technologies, the revenues from selling electricity in power markets as well as the costs which come from buying fuels at uncertain market prices must be evaluated over very long time horizons, i.e., over the whole lifetime of the plants. Starting from accurate short-term stochastic models of fuel prices in addition to electricity prices, we provide long-run probability distributions which are used to compute revenues and costs incurring during the whole lifetime of the plants. Five sources of uncertainty are taken into account, namely electricity market prices, fossil fuel prices (natural gas and coal prices), nuclear fuel prices and $\mathrm{CO}_{2}$ prices. Our evaluation model is calibrated on empirical data to account for both historical market prices and macroeconomic views about future trends of electricity and fuel prices. The full probability density of the stochastic Net Present Value is thus determined for each generation technology considered in this study.
\end{abstract}

Keywords Regime-switching stochastic processes $\cdot$ Mean-reversion $\cdot$ Probabilistic long-term forecasting $\cdot$ Stochastic net present value $\cdot$ Stochastic levelized cost of electricity

JEL Classification G31 $\cdot \mathrm{G} 32 \cdot \mathrm{G} 33 \cdot \mathrm{M} 21 \cdot \mathrm{Q} 40$

Carlo Mari

carlo.mari@unich.it

1 Department of Economics, University of Chieti-Pescara, 65127 Pescara, Italy 


\section{Introduction}

Started at the beginning of the 1990s, the liberalization process of the electricity sector engaged several countries worldwide with the aim of transforming existing monopolistic markets into competitive markets. Such competitive markets were properly designed for allowing trades of electricity as a new commodity and were organized to discover equilibrium prices through demand and supply balancing. Electricity has, in fact, very peculiar characteristics [13]. It cannot be stored in an economically convenient way. Its transmission requires a constant balancing between injections to and withdrawals from the power grid. Moreover, electricity has a highly inelastic demand curve, strongly dependent on weather conditions (temperature, wind speed, precipitation, etc.). Supply is, in general, provided by low marginal costs generators but, in many cases, the mismatch between supply and demand, as for instance peaks in electricity demand, can be satisfied at very high costs $[13,50]$. Given all this, it is not hard to understand how the liberalized marked interaction between demand and supply has dramatically increased the short-term volatility of power prices: shortages in electricity generation due to forced outages and/or grid congestions, peaks in electricity demand, fluctuations in hydroelectricity production, may result in unanticipated jumps in power prices and spikes of very high amplitude. These peculiarities have led to very erratic price dynamics not observed in any other commodity or financial market [48].

In the face of this, accurately modeling and forecasting electricity price dynamics becomes a crucial task for designing effective short-term trading strategies and long-term investments in power generating technologies. Namely, at the corporate level short- and long-term electricity price forecasts are very important from the producer's perspective $[13,53]$. On one hand short-term price forecasts are of particular interest for defining bidding strategies [5] and scheduling production in order to maximize trading profits or hedge financial risk [4, 49]. On the other hand price forecasts on longer time horizons, ranging from a few years to decades, are of strategic importance for valuing investments in new generating technologies and for power planning decision making of energy companies and policy makers. Providing a link between accurate short-term modeling and longterm behavior of electricity prices is thus an important and necessary task.

Short-term price forecasting techniques are well developed in the literature, both for point and for probabilistic forecasting. A standard reference for price point forecasting is the in-depth review proposed by Weron [49]. Probabilistic forecasting consists of forecasting the whole price distribution or some related parts, as for example quantiles, at a time not too far in the future. Short-term probabilistic forecasting was recently reviewed by Nowotarski and Weron [40]. On the other side, long-run forecasting of electricity prices has not yet been investigated as much. This fact might be due to a limited understanding of the main drivers of the most important variables which affect electricity prices over long time horizons, as fossil fuel prices, environmental policies regarding $\mathrm{CO}_{2}$ emissions, technological changes, smart grid evolution, etc. [47]. Although some methods for long-term point forecasting electricity prices and their volatilities are 
proposed in the literature (see, e.g., $[1,15]$ ), papers on probabilistic forecasting methods, in which the probability density function of electricity prices is forecast, are few and they are mainly devoted to mid-term forecasting ranging from 1 month to 1 year $[2,3]$. A review on probabilistic mid- and long-term electricity price forecasting was discussed by Ziel and Steinert [54]. In the same paper, the Authors proposed also a probabilistic approach to forecast electricity prices for several months up to 3 years. However, valuing investments in new generating technologies requires to take into account forecasts of revenues from selling electricity at market prices and their volatilities for decades, i.e., over the whole lifetime of the plant. The present paper aims to fill this gap in the literature by introducing a new probabilistic approach to long-term forecasting in order to simulate revenues distributions over very long time horizons.

We propose a long-term forecasting methodology in which the long-run behavior of power prices is derived from the short-term dynamics. To this end, we will start from accurately modeling short-term random movements of electricity prices and we will end up to provide probability distributions in the long-run. In particular, we discuss three short-term stochastic models. In the first model, which we will name 'Model 1', the dynamics of electricity prices is described by a mean-reverting diffusion process. In the second model, i.e., 'Model 2', a mean-reverting jump-diffusion process is used to describe the dynamics of prices. Finally, in the third model, i.e., 'Model 3', the dynamics of electricity prices is described by a mean-reverting two regime-switching Markov process. Mean-reversion is a very relevant feature of the electricity price behavior observed in power markets. First, it is responsible for reducing prices after a spike has occurred; second, it forces the stochastic component of prices to fluctuate around some long-run mean, driving probability densities toward stationary long-run distributions. By the use of mean-reversion, the shortterm dynamics can be connected to the long-term behavior of power prices. Moreover, these models can be calibrated on historical data and can include a structural component in terms of forward looking information based on macroeconomic views about the future long-term evolution of electricity prices. In this way, the proposed approach develops a robust link between accurate short-term modeling and longterm behavior of electricity prices. This is one of the novelty aspects of the present paper and the first main contribution to the literature.

Long-run forecasting is an important topic of research. When an electricity company plans to build new power plants, it needs long-term revenues and generation cost forecasts over the whole lifetime of the plants, basing its decision-making on some long-term metrics as, for example, the Net Present Value (NPV) of the investment [24]. The NPV criterion is a widespread method suitable for long-term evaluation [31, 45] that takes into account revenues from selling electricity in power markets and costs incurred during the whole lifetime of the plants. In addition, the stochastic NPV theory, which attributes to the NPV a probability distribution, provides a powerful tool to perform risk analysis of investments [45].

As a second contribution to the existing literature, we discuss an evaluation scheme for risky investments in new baseload generating technologies, namely fossil fuel (gas and coal) power plants and nuclear power plants, based on the stochastic NPV as a long-term metric. The stochastic NPV is computed under accurate 
modeling of the stochastic dynamics of the main factors affecting the profitability of the investment. In this regard, five sources of uncertainty are taken into account, namely electricity market prices, fossil fuel prices (natural gas and coal prices), nuclear fuel prices and $\mathrm{CO}_{2}$ prices. Market based $\mathrm{CO}_{2}$ pricing schemes (like the European Union Emissions Trading Scheme, EU-ETS) generate volatility in $\mathrm{CO}_{2}$ prices $[14,38]$ through the interaction between demand and supply, thus introducing a new source of uncertainty which must be taken into account for valuing investments in power generation technologies [20]. These factors are the main financial risk sources in the electricity sector $[15,26]$. Since the analysis is limited to baseload technologies, quantity uncertainty has a minor effect and it is not taken into account. Regarding the nuclear source, we do not consider here the financial risk due to the social acceptance of this technology. The reason is that we assume that the investment evaluation is performed in a case in which the nuclear power generation is a well accepted technology. Although in principle construction costs could be stochastic, especially for nuclear power plants [27], we do not consider here this possibility. However, the model can be extended to account for uncertainty in all types of costs.

The novelty of this approach is to provide a model to value investments in new baseload generating technologies in a stochastic framework in which random movements of electricity and fuel prices are accurately modeled both in the short- and in the long-term. The starting point of our analysis is modeling the short-term behavior and then investigate the long-term limit in order to compute stochastic revenues and costs during the whole lifetime of the plants. Regarding the electricity price dynamics, we use the regime-switching Model 3 that better describes the random movements of electricity prices observed in real markets with respect to Model 1 and Model 2 (as it is will shown in the following). From the costs side, fuel prices too are modeled according to well defined stochastic processes. In particular, since gas market prices exhibit mean-reversion and jumps, we use a mean-reverting jump-diffusion model to capture the features of the short-term dynamics of gas prices. Coal and nuclear fuel prices do not show mean-reversion and we assume that their time evolution are both described by a Geometric Brownian Motion (GBM). As a further source of uncertainty, we will consider the possibility to include $\mathrm{CO}_{2}$ costs into the analysis. $\mathrm{CO}_{2}$ prices will be modeled according to a GBM. As suggested in the literature, the long-run analysis of investments in the power sector must integrate historical data and future trends in market prices, including expert evaluations of future regulations and forthcoming technologies [19]. The evaluation model we propose can be calibrated on historical data on market prices and can incorporate a structural component in terms of macroeconomic views about future trends of electricity and fuel prices. This approach allows us to determine the probability density of stochastic NPVs of new generating technologies and to perform risk analysis of investments in capacity expansion. The empirical analysis, based on cost data of new generating technologies collected from the 'Annual Energy Outlook 2019' [9] reveals that, with the exception of the gas generation, both coal and nuclear power generation show a negative expected NPV. This is an important result which can be useful for both investors and policy makers in their efforts to plan capacity expansion and future power system configurations. This is the third main contribution to the literature. 
It could be interesting to relate our approach to more structural approaches to long-term price setting and forecasting. For example, in the model proposed by Oliveira and Costa [41] a fictional microeconomic dynamics drives the market to an equilibrium, which is reached by groping and mutual learning by part of the market agents. Since the dynamics is fictional, no information can be given about the real dynamics which will go on inside the period studied. In the model proposed by De Vries and Heijnen [8], the specific aim is understanding how the dynamics of electricity generation capacity growth can be stimulated and controlled in time, within a long-term horizon. In this case, demand and supply changes are matched in time under different regulatory and legislation schemes, and under demand growth uncertainty. Together, these two approaches can be taken as examples of possible ways to tackle with one of the most important facts behind long-term price valuation. Price forecasting on long time horizons means taking into account a capacity expansion problem and its impact on prices [6], especially in the presence of variable renewable energy (VRE) sources [52]. It is certainly not easy to include this feature into long-term forecasting models. In any case, making an econometrics of prices emerge from matching demand with supply is in the end deeply linked to our approach. In a different but twin way, the stochastic NPV assessment tries to model a decision process under uncertainty, yet without directly coping with the microstructure of the power market. In our approach, the effects of the microstructure are included in the phenomenology of historical power and fuel prices, and we indirectly include it by calibrating the model on empirical data related to historical market prices over long time horizons and on macroeconomic forward looking views about future trends of electricity, fuel and $\mathrm{CO}_{2}$ market prices.

The paper is organized as follows. Section 2 discusses the short-term dynamics of electricity prices. Some models are introduced and estimated on historical data from Palo Verde and PJM markets. In Sect. 3, the long-term behavior of electricity prices is investigated, and stationary probability distributions are derived and discussed. Section 4 introduces the stochastic NPV metric and its link with the stochastic Levelized Cost Of Electricity (LCOE). Sections 5 and 6 concern the stochastic modeling of revenues and costs respectively. In Sect. 7, a stochastic NPV based analysis of investments in new generating technologies is provided. Section 8 concludes. Finally, "Appendix" provides some technical results about the time evolution of central moments in the jump-diffusion model.

\section{Modeling electricity price dynamics}

Figure 1 depicts the time series of daily electricity prices observed between January, 2009 and December, 2018 at the two US power markets of Palo Verde (US Southwest region) and PJM (US Northeast region). Daily prices are obtained as weighted averages of the 24 hourly market prices and are expressed in nominal dollars per megawatthour $(\$ / M W h)$. These electricity price time series are available at www. eia.gov/electricity/wholesale and are freely downloadable.

Looking at Fig. 1, we note that electricity prices follow a very erratic dynamics characterized by high volatility, jumps and pronounced spikes. Moreover, 

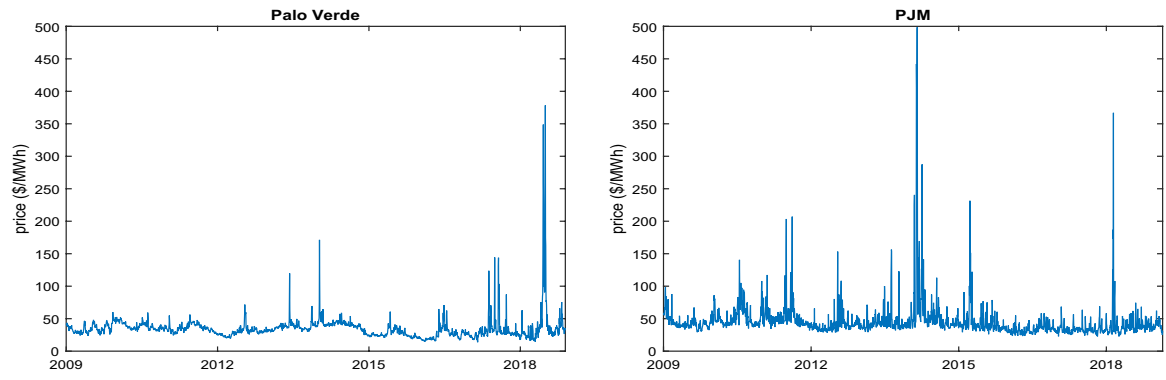

Fig. 1 Historical behavior of power prices at Palo Verde market (left) and at PJM market (right) since January, 2009-December, 2018

multi-regime dynamics can be observed. In normal stable periods, prices fluctuate around some long-run mean; in turbulent periods prices experience jumps and short-lived spikes. After a jump or a spike has occurred, a mean-reversion mechanism forces back prices to fluctuate around some long-run mean. Accurate modeling power price dynamics means to take into account all these features.

Several continuous-time models for electricity prices were proposed in the literature. Since the seminal paper by Lucia and Schwartz [30], in which a mean-reverting diffusion process was proposed to model the power price dynamics at the Nord Pool market, the literature on this topics has grown exponentially. Mean-reverting jumpdiffusion processes and mean-reverting regime-switching models were extensively used to accurately describe the jumpy and the spiky behavior of electricity prices observed in power markets. In this section we focus on three models of these types, namely a mean-reverting diffusion model, a mean-reverting jump-diffusion model, and mean-reverting two regime-switching model.

Let us denote by $P(t)$ the daily price at time $t$ of one MWh of electricity, and by $s(t)=\ln P(t)$ its natural logarithm. We assume that $s(t)$ is a linear superposition of a deterministic component, $f(t)$, possibly accounting for trend and seasonality, and a random component, $x(t)$, namely

$$
s(t)=f(t)+x(t) .
$$

Since electricity prices may be higher in winter time and in summer time, we express the deterministic component as

$$
f(t)=b_{0}+b_{1} t+b_{2} \cos \left(b_{3}+\frac{2 \pi t}{\tau}\right)+b_{4} \cos \left(b_{5}+\frac{4 \pi t}{\tau}\right),
$$

to describe the semiannual periodicity. A linear trend is included to account for expected inflation and possibly for a real escalation rate of power prices (positive or negative). The parameter $\tau$ denotes the average number of observations per year. One can estimate the seasonal component parameters $b_{j}(j=0,2, \cdots, 5)$ by fitting $f(t)$ to market data using Ordinary Least Squares (OLS) techniques. Table 1 depicts the parameters estimates obtained in the Palo Verde and PJM power markets.

Figure 2 shows the time series of stochastic log-returns (hereinafter, log-returns) obtained as daily changes of the random component $x(t)$, at Palo Verde market (left 
Table 1 Parameter estimates of the deterministic component

\begin{tabular}{lllllll}
\hline & $b_{0}$ & $b_{1}$ & $b_{2}$ & $b_{3}$ & $b_{4}$ & $b_{5}$ \\
\hline Palo Verde & 3.6022 & $-0.0933 \times 10^{-3}$ & -0.1553 & -0.8087 & 0.1065 & -0.5117 \\
PJM & 3.9192 & $-0.1364 \times 10^{-3}$ & -0.0196 & 0.5443 & 0.0930 & -0.6625 \\
\hline
\end{tabular}
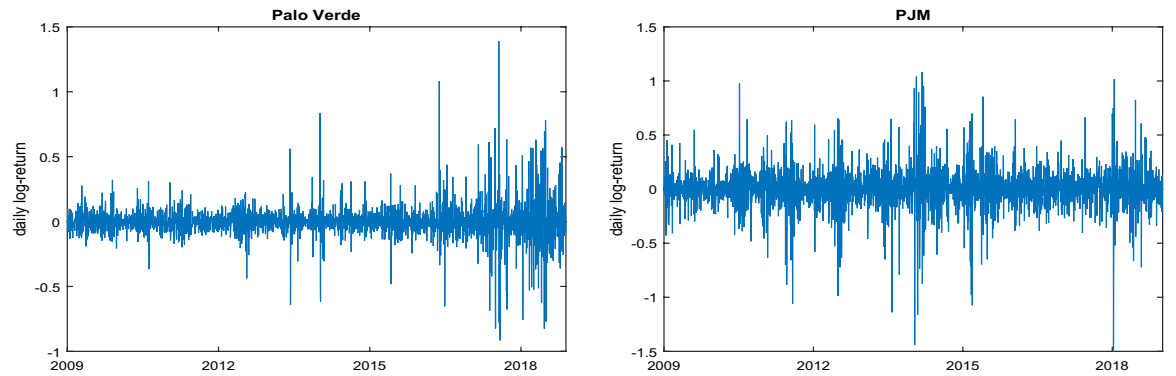

Fig. 2 Historical behavior of log-returns at Palo Verde market (left) and at PJM market (right) since January, 2009-December, 2018

Table 2 Descriptive statistics of log-returns

\begin{tabular}{lllll}
\hline & Mean & St. dev. & Skewness & Kurtosis \\
\hline Palo Verde & 0.0000 & 0.1320 & 0.5615 & 19.2915 \\
PJM & -0.0001 & 0.1968 & -0.3272 & 10.8712 \\
\hline
\end{tabular}

panel) and at PJM market (right panel). Descriptive statistics of log-returns are displayed in Table 2 .

As mentioned in Sect. 1, and as it can be seen also in the figure, interplay between demand and supply generates a lot of volatility in nowadays power markets. Log-returns show large fluctuations with jumps and spikes, and non-normal, leptokurtic empirical distributions. With the aim of capturing the features of log-returns observed in these markets, we discuss now three continuous-time stochastic models for the dynamics of $x(t)$, called, respectively, Model 1, Model 2 and Model 3. The main features of these models are described below.

\subsection{Model 1}

In Model 1, the dynamics of $x(t)$ is described by the following mean-reverting diffusion process,

$$
d x(t)=-\alpha_{0} x(t) d t+\sigma_{0} d w_{0}(t)
$$

where $\alpha_{0}$ is the mean-reversion parameter, $\sigma_{0}$ is the volatility, and $w_{0}(t)$ is a Wiener process. Although this model captures the mean-reverting behavior of power prices, 
it is not able to account for jumps and spikes. This limitation can be overcome by modeling power price dynamics with a jump-diffusion process.

\subsection{Model 2}

In Model 2 the dynamics of $x(t)$ is described by a mean-reverting jump-diffusion process of the form

$$
d x(t)=-\alpha_{0} x(t) d t+\sigma_{0} d w_{0}(t)+J d q(t)
$$

where $q(t)$ is a Poisson process with constant intensity $\lambda$. In Eq. (4) the random jump amplitude $J$ is distributed as a Gaussian random variable with zero mean and standard deviation $\sigma_{J}$, i.e. $J \sim N\left(0, \sigma_{J}^{2}\right)$. We assume that the Wiener process, the Poisson process, and the jump amplitude are mutually independent processes. We remark that the zero mean jump amplitude was chosen according to the observed low values of the skewness present in the data (see Table 2). Nevertheless, the proposed analysis is general and can be extended in a straightforward way to include jumps with arbitrary probability distributions (see "Appendix ").

\subsection{Model 3}

Model 3 consists of a regime-switching process with two regimes. Regime-switching processes add a further degree of freedom to the description of the dynamics of electricity prices. In our specific, they allow us to combine in one model periods of steady dynamics and of jumpy dynamics, depending on the realization of a stochastic twovalued latent state variable of the system. We can thus make use of two different statedependent mean-reversion rates and include stochastic volatility. Model 3 is characterized by the following process,

$$
d x(t)=\left\{\begin{array}{l}
-\alpha_{0} x(t) d t+\sigma_{0} d w_{0}(t), \\
-\alpha_{1} x(t) d t+\sigma_{1} d w_{1}(t)+J d q(t) .
\end{array}\right.
$$

The dynamics of the base regime (first line of Eq. 5) is described by a mean-reverting diffusion process in order to account for the motion during stable periods. In contrast, the dynamics of the jumpy regime (second line of Eq. 5) is described by a mean-reverting jump-diffusion process. As in the two previous models, $w_{0}(t)$ and $w_{1}(t)$ are Wiener processes and $q(t)$ is a Poisson process with constant intensity $\lambda$. In Eq. (5) the random jump amplitude $J$ is distributed as a Gaussian random variable with zero mean and standard deviation $\sigma_{J}$, i.e., $J \sim N\left(0, \sigma_{J}^{2}\right)$. We assume that the Wiener processes, the Poisson process, and the jump amplitude, are mutually independent processes. The switching between regimes is driven by a hidden Markov process characterized by the following transition probability matrix,

$$
\pi=\left(\begin{array}{cc}
1-\gamma d t & \eta d t \\
\gamma d t & 1-\eta d t
\end{array}\right)
$$


Table 3 Palo Verde estimation results

\begin{tabular}{llll}
\hline & Model 1 & Model 2 & Model 3 \\
\hline$\alpha_{0}$ & 0.1094 & 0.0616 & 0.0301 \\
& $(0.0058)$ & $(0.0073)$ & $(0.0050)$ \\
$\sigma_{0}$ & 0.1283 & 0.0675 & 0.0549 \\
& $(0.0032)$ & $(0.0020)$ & $(0.0016)$ \\
$\lambda$ & & 0.1230 & 0.2017 \\
& & $(0.0062)$ & $(0.0206)$ \\
$\sigma_{J}$ & & 0.3135 & 0.3693 \\
& & $(0.0117)$ & $(0.0298)$ \\
$\alpha_{1}$ & & & 0.1469 \\
& & & $(0.0123)$ \\
$\sigma_{1}$ & & & 0.1168 \\
& & & $(0.0063)$ \\
$1-\gamma$ & & & 0.9678 \\
& & & $(0.0047)$ \\
$1-\eta$ & & & 0.9393 \\
& & & $(0.0274)$ \\
LL & 1568.3 & 2259.9 & 2491.1 \\
SC & -3120.9 & -4488.6 & -4919.7 \\
\hline
\end{tabular}

Standard errors are between parentheses

where $\gamma d t$ denotes the transition probability of a switch from the base regime to the turbulent regime in the infinitesimal time interval $[t, t+d t]$, and $\eta d t$ is the probability of the opposite transition.

All these models were estimated on market data by maximum likelihood using the Euler discretization with time step $\Delta t$ equal to 1 day. In the case of Model 3, the Hamilton filtering technique [17, 18] was used. Estimation results are depicted in Table 3 for the Palo Verde market, and in Table 4 for the PJM. For each market, the parameters estimates, the log-likelihood (LL), and the value of the Schwartz criterion (SC) are reported.

As it can be read from the last line of these tables the empirical analysis reveals that the regime-switching model describes the dynamics of electricity prices better than diffusion and jump-diffusion models. The Schwartz criterion indicates that the presence of jumps in the dynamics enhances the fit. Moreover, the added degrees of freedom coming from multiple mean-reversion rates and volatilities (i.e., for the base and the turbulent regime), makes regime-switching models more suitable to describe the dynamics of electricity prices observed in real markets $[32,37]$. As expected, the mean-reversion parameter as well as the volatility parameter are lower in the base regime with respect to the turbulent one. The statistical analysis of simulated trajectories confirms that regime-switching models offer an interesting agreement with market data. Tables 5 and 6 display some parameters computed from simulated log-returns time series. Such values are computed averaging over ten thousands randomly generated paths using, respectively, Palo Verde and PJM estimates to be compared with the statistics 
Table 4 PJM estimation results

\begin{tabular}{llll}
\hline & Model 1 & Model 2 & Model 3 \\
\hline$\alpha_{0}$ & 0.2075 & 0.1684 & 0.1213 \\
$\sigma_{0}$ & $(0.0092)$ & $(0.0123)$ & $(0.0077)$ \\
& 0.1863 & 0.1182 & 0.0968 \\
$\lambda$ & $(0.0034)$ & $(0.0050)$ & $(0.0059)$ \\
& & 0.1589 & 0.1856 \\
$\sigma_{J}$ & & $(0.0104)$ & $(0.0158)$ \\
& & 0.3624 & 0.4317 \\
$\alpha_{1}$ & & $(0.0325)$ & $(0.0250)$ \\
& & & 0.2643 \\
$\sigma_{1}$ & & & $(0.0234)$ \\
& & & 0.2022 \\
$1-\gamma$ & & & $(0.0059)$ \\
& & & 0.9422 \\
$1-\eta$ & & & $(0.0051)$ \\
$\mathrm{SC}$ & & & 0.9057 \\
\hline $\mathrm{Sta}$ & & & $(0.0051)$ \\
& & & 1142.6 \\
& & & -2222.5 \\
\hline & & &
\end{tabular}

Standard errors are between parentheses

Table 5 Statistics of simulated path log-returns obtained using Palo Verde estimated parameters

\begin{tabular}{llll}
\hline & Model 1 & Model 2 & Model 3 \\
\hline Mean & -0.0001 & -0.0001 & -0.0001 \\
& $(0.0001)$ & $(0.0001)$ & $(0.0001)$ \\
St. dev. & 0.1320 & 0.1308 & 0.1310 \\
& $(0.0019)$ & $(0.0048)$ & $(0.0090)$ \\
Skewness & 0.0015 & 0.0065 & 0.0025 \\
& $(0.0496)$ & $(0.3592)$ & $(0.4734)$ \\
Kurtosis & 2.9963 & 13.4739 & 17.2018 \\
& $(0.0956)$ & $(1.3415)$ & $(2.7836)$ \\
\hline
\end{tabular}

Standard deviations are between parentheses

from original data shown in Table 2. We can observe that the statistical analysis of simulated trajectories shows an interesting agreement with market data in the case of Model 3.

We conclude this section by noticing that Palo Verde and PJM markets are characterized by very different values of the mean-reversion rate. In all the models which we discussed, mean-reversion parameters estimated on Palo Verde market data are lower than those estimated on PJM market data. As we will see in the following sections, this fact has important consequences on the long-run behavior of electricity prices. 
Table 6 Statistics of simulated path log-returns obtained using PJM estimated parameters

\begin{tabular}{llll}
\hline & Model 1 & Model 2 & Model 3 \\
\hline Mean & 0.0000 & 0.0000 & 0.0000 \\
& $(0.0001)$ & $(0.0001)$ & $(0.0001)$ \\
St. dev. & 0.1968 & 0.1950 & 0.1970 \\
& $(0.0028)$ & $(0.0056)$ & $(0.0084)$ \\
Skewness & -0.0018 & -0.0022 & -0.0053 \\
& $(0.0462)$ & $(0.1961)$ & $(0.2431)$ \\
Kurtosis & 2.9943 & 7.7619 & 9.5101 \\
& $(0.0972)$ & $(0.7079)$ & $(1.2655)$ \\
\hline
\end{tabular}

Standard deviations are between parentheses

\section{Long-term evolution of electricity prices}

The long-term behavior of electricity prices can be investigated by studying the time evolution of the central moments of log-price distributions. Central moments are defined by

$$
M_{n}(t)=E\left[(x(t)-\mu(t))^{n}\right],
$$

where $\mu(t)=E[x(t)]$ denotes the expected value of the random variable $x(t)$. In both Model 1 and Model 2 if $x(0)=x_{0}$ is the initial condition of the process, $\mu(t)$ is given by

$$
\mu(t)=x_{0} e^{-\alpha t}
$$

In these two models, closed form solutions for central moments can be found. In particular, odd central moments are zero and the first two even moments are given by

$$
M_{2}(t)=\frac{\sigma^{2}}{2 \alpha}\left(1-e^{-2 \alpha t}\right)
$$

and

$$
M_{4}(t)=3\left[\frac{\sigma^{2}}{2 \alpha}\left(1-e^{-2 \alpha t}\right)\right]^{2}=3 M_{2}(t)^{2}
$$

in Model 1, and by

$$
M_{2}(t)=\frac{\sigma^{2}+\lambda \sigma_{J}^{2}}{2 \alpha}\left(1-e^{-2 \alpha t}\right)
$$

and 


$$
M_{4}(t)=\frac{3 \lambda \sigma_{J}^{4}}{4 \alpha}\left(1-e^{-4 \alpha t}\right)+3 M_{2}(t)^{2}
$$

in Model 2. The proofs of the above equations as well as the proofs of the formulas presented in this section are provided in A.

It is well known that $x(t)$ are normal variables for $t>0$ in Model 1 [16], but they are not normal in Model 2, as it can be verified by the value of the kurtosis which is different from 3. In the limit $t \rightarrow \infty$, central moments converge toward stationary values that can be computed by using the recursive relationship

$$
M_{2 n}=\frac{2 n-1}{2 \alpha} \sigma^{2} M_{2(n-1)}
$$

in Model 1, and by

$$
M_{2 n}=\frac{2 n-1}{2 \alpha} \sigma^{2} M_{2(n-1)}+\frac{\lambda}{2 n \alpha} \sum_{k=1}^{n} \frac{(2 n) !}{2^{k} k !(2 n-2 k) !} \sigma_{J}^{2 k} M_{2(n-k)}
$$

in Model 2. The stationary value of the kurtosis is $K=3$ in Model 1, and

$$
K=3+3 \frac{\lambda \sigma_{J}^{4}}{\alpha\left(\sigma^{2}+\sigma_{J}^{2}\right)^{2}},
$$

in Model 2. Figure 3 depicts the time behavior of standard deviation and kurtosis, computed with estimated parameters at Palo Verde and PJM markets for both Model 1 and Model 2.

In market data, probability distributions tend to be stationary in a few tens of days. After this time interval, the process random variables $x(t)$ and $x(s)$ become identically distributed for any time $t$ and time $s$. The speed of convergence to the stationary distribution depends, of course, on the mean-reversion parameter. The convergence is, therefore, faster for PJM market prices. Moreover, random variables $x(s)$ and $x(t)(t \geq s)$ become uncorrelated in a few tens of days. To show this, we notice that the autocorrelation function can be computed in a closed form in both models and reads,

$$
\operatorname{Cov}(x(s), x(t))=\frac{\sigma^{2}}{2 \alpha}\left[e^{-\alpha(t-s)}-e^{-\alpha(t+s)}\right]
$$

in Model 1, and

$$
\operatorname{Cov}(x(s), x(t))=\frac{\sigma^{2}+\lambda \sigma_{J}^{2}}{2 \alpha}\left[e^{-\alpha(t-s)}-e^{-\alpha(t+s)}\right],
$$

in Model 2. For large $s$, i.e., after some tens of days, the autocorrelation function becomes stationary in both Model 1 and Model 2. It depends on the time difference, $s-t$, with a correlation coefficient which decreases exponentially, 

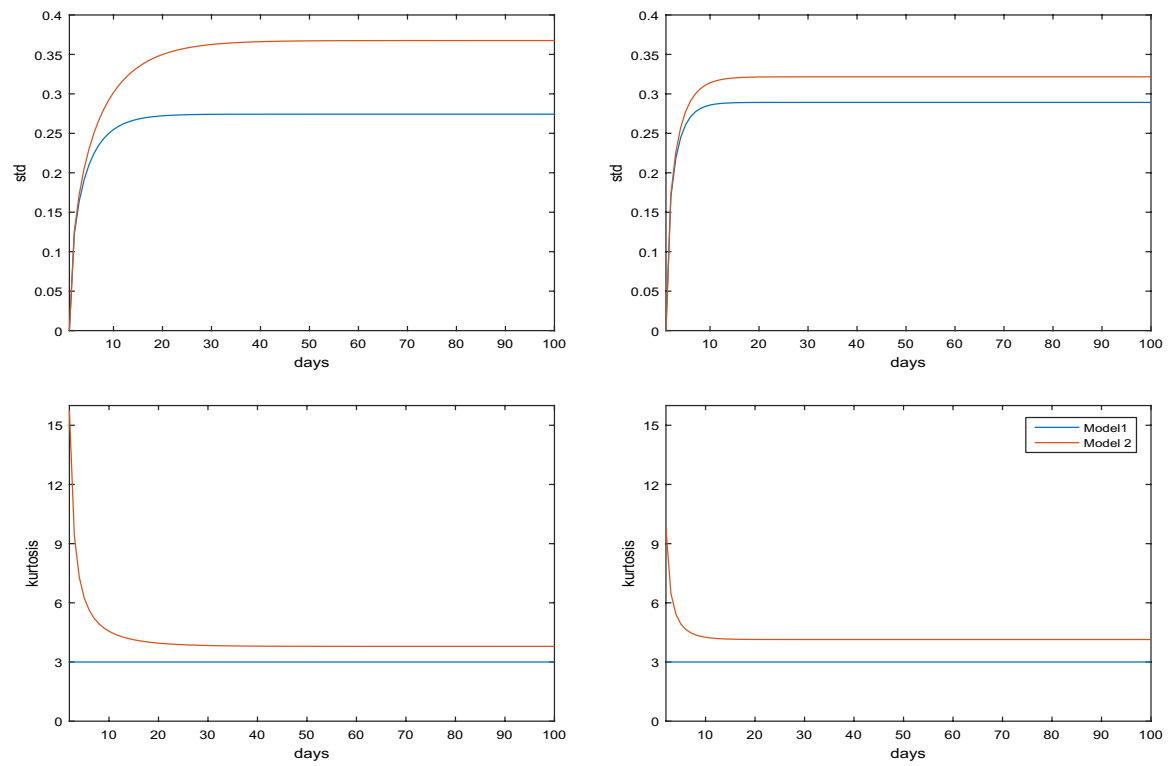

Fig. 3 Time behavior of standard deviation and kurtosis simulated using Palo Verde (left panels) and PJM (right panels) estimated parameters

$$
\rho(s, t)=e^{-\alpha(t-s)},
$$

in both Model 1 and Model 2. A more complicated structure arises when Model 3 is considered and no closed form solutions for central moments can be found. Moreover, differently from Model 1 and Model 2, the time evolution of the central moments depends on the initial condition of the stochastic dynamics.

Figure 4 shows the time behavior of the mean, standard deviation, skewness and kurtosis (hereinafter, the first four moments) obtained by Monte Carlo simulations using estimated parameters at Palo Verde and PJM markets respectively. Simulations were performed under two very different initial conditions, namely $x(0)=0$ and $x(0)=3$. The first value was chosen equal to the long-run mean value of $x(t)$, the second value was chosen very far from the long-run mean value (it corresponds to an electricity price greater than one thousand dollars). In both cases, standard deviation and kurtosis converge rapidly (in some tens of days) to their stationary values. The mean and the skewness converge rapidly to zero. The convergence is faster in the PJM market because of larger values of the mean reversion parameters. Moreover, random variables $x(t)$ and $x(s)(s \geq t)$ become uncorrelated in some tens of days. Figure 5 depicts the time behavior of the correlation coefficient in the time interval of $[0,150]$ days simulated by using Palo Verde and PJM estimated parameters. In each panel, the blue line refers to the initial condition $x(0)=0$, and the red line to the initial condition $x(0)=3$. The third (yellow) line shows the time behavior of the stationary correlation coefficient. Of course, the stationary autocorrelation function does not depend on the initial condition of the dynamics. Due to higher mean-reversion values, both in the base 

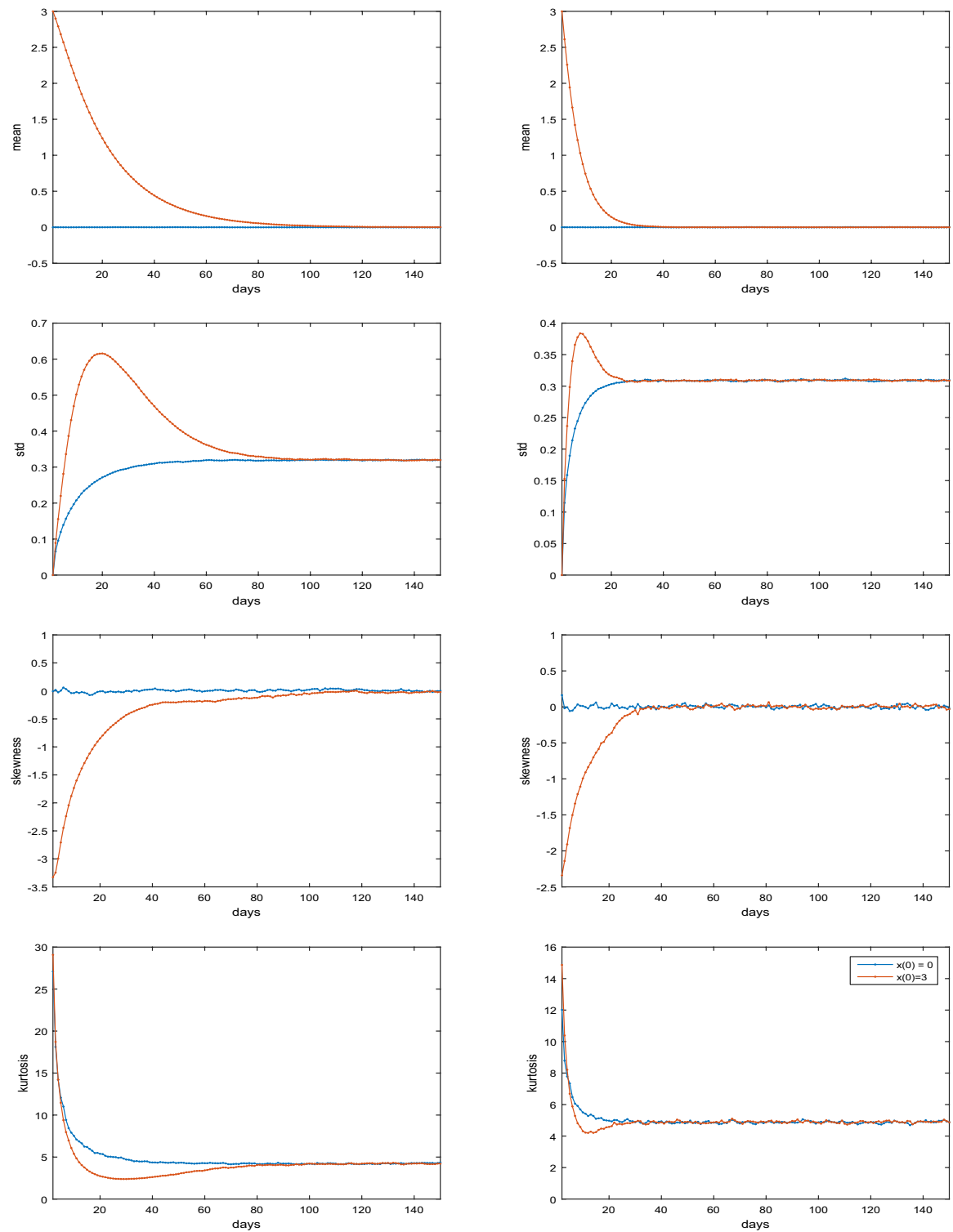

Fig. 4 Time behavior of the first four moments simulated using estimated parameters at Palo Verde market (left panels) and at PJM (right panels). The initial condition is set at $x(0)=0$ (blue line) and $x(0)=3$ (red line)

regime and in the turbulent regime, the convergence toward zero correlation is faster for PJM market prices.

The discussed results are very useful to investigate the long-term behavior of electricity prices. Valuing investments in the power sector for new generating capacity requires to take into account revenues from selling electricity on power market 

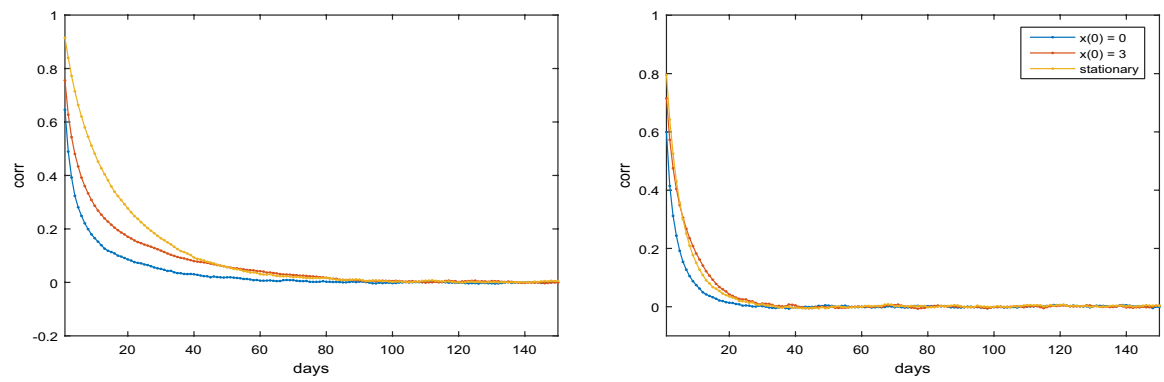

Fig. 5 Time behavior of the correlation coefficient simulated by using Palo Verde (left panel) and PJM (right panel) estimated parameters

Fig. 6 Project timeline

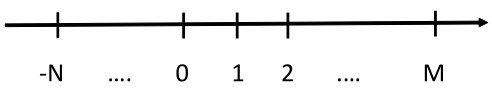

for decades. We will see that such results can be used to conciliate accurate descriptions of short-term behavior with long-term macroeconomic views about future trends of electricity prices.

\section{The stochastic net present value of power generation and the stochastic levelized cost of electricity}

The stochastic Net Present Value (NPV) and the stochastic Levelized Cost Of Electricity (LCOE) are mathematical constructs that allow us to introduce risk into the evaluation process of investments in new generating technologies [28, 45]. As specified in the Introduction, we will consider in this paper five sources of risk, namely the risk associated to random movements of (1) electricity prices, (2) gas, (3) coal prices, (4) nuclear fuel and (5) $\mathrm{CO}_{2}$ prices.

To briefly introduce some basic concepts about stochastic NPV and LCOE, let us consider an investment project in a generating plant, financially seen as a cashflow stream defined on a yearly timetable (as depicted in Fig. 6). We denote by $n=-N<0$ the construction starting time, and by $n=0$ the end of construction time. The time $n=0$ is also the starting time of the operations, and $n=M \geq 1$ is the end of operations time. The cash-flow evaluation time is $n=0$.

We suppose that there are $k$ risk sources and we denote by $\xi$ the risky sources stochastic path. The unlevered cash-flow generated by the project at time $n, F_{n}^{z}$, can be expressed as follows,

$$
F_{n}^{z}(\xi)=R_{n}^{z}(\xi)-C_{n}^{z}(\xi)-T_{n}^{z}(\xi), \quad n=1,2, \ldots, M,
$$

where $R_{n}^{z}(\xi)$ accounts for stochastic revenues from selling electricity, $C_{n}^{z}(\xi)$ for stochastic costs, and $T_{n}(\xi)$ for income taxes in the year $n$. Revenues, costs, and taxes incurring in the time interval $[n-1, n]$ are computed as lump sums and valued at time $n$. All these quantities are expressed in nominal terms. The cost term in Eq. (19) includes all the costs incurred during the whole the operational lifetime of 
the plant, namely fixed and variable operation and maintenance (O\&M) costs, fuel costs (not included in the variable O\&M costs), waste management (for nuclear generation) and decommissioning costs. With regard to fossil fuels, costs can include externalities, i.e., environmental costs like $\mathrm{CO}_{2}$ market costs.

In the classic definition, the NPV of an investment in the generating technology $z$ is determined by the difference between the present value of expected revenues and the present values of expected costs and taxes including pre-operations investment costs. NPV can be, then, determined by subtracting investment costs from the present value of the unlevered cash-flow. To compute the present value, the unlevered cash-flow must be discounted at the Weighted Average Cost of Capital (WACC) nominal rate [46]. If we denote by $r$ the nominal WACC rate on an annual basis, the NPV formula reads

$$
N P V^{z}=\sum_{n=1}^{M} \frac{E\left[F_{n}^{z}(\xi)\right]}{(1+r)^{n}}-I_{0}^{z}
$$

In Eq. (20) $I_{0}^{z}$ is the pre-operations nominal investment, starting at $n=-N$ and ending at $n=0$, computed as a lump sum, namely as

$$
I_{0}^{z}=\hat{I}_{-N}^{z}(1+r)^{N}+\cdots+\hat{I}_{-1}^{z}(1+r)+\hat{I}_{0}^{z},
$$

where $\hat{I}_{n}^{z}$ is the nominal amount of the construction cost allocated to year $n$. Following the MIT $[34,35]$ analytical approach, yearly tax liabilities are computed by subtracting costs and asset depreciation from sales revenues, thus getting

$$
T_{n}^{z}(\xi)=T_{c}\left[R_{n}^{z}(\xi)-C_{n}^{z}(\xi)-D_{n}^{z}\right]
$$

where $D_{n}^{z}$ is the fiscal depreciation. Finally, revenues from electricity sales can be cast as follows,

$$
R_{n}^{z}(\xi)=Q^{z} P_{n}^{z}(\xi)
$$

where $Q^{z}$ is the amount of electricity generated by the technology $z$ in 1 year ${ }^{1}$, and $P_{n}^{z}(\xi)$ is the (yearly averaged) unitary selling price of the electricity produced in the year $n$ by the technology z. By substituting Eq. (19) into Eq. (20) and accounting for Eqs. (22) and (23), after some algebraic manipulations, we get

\footnotetext{
${ }^{1} Q^{z}$ is assumed to be constant over time and can be computed by multiplying the nameplate power capacity of the plant, $W^{z}$, by the capacity factor of that plant, $C F^{z}$, and by the number of hours in 1 year (8760), i.e,

$$
Q^{z}=8760 \times C F^{z} \times W^{z}
$$
}




$$
\begin{aligned}
N P V^{z}= & \left(1-T_{c}\right) Q^{z} \sum_{n=1}^{M} E\left[P_{n}^{z}(\xi)\right] F_{0, n}+ \\
& -\left(1-T_{c}\right) \sum_{n=1}^{M} E\left[C_{n}^{z}(\xi)\right] F_{0, n}+T_{c} \sum_{n=1}^{M} D_{n}^{z} F_{0, n}-I_{0}^{z},
\end{aligned}
$$

where we posed

$$
F_{0, n}=\frac{1}{(1+r)^{n}}
$$

Equation (24) can be also used as a starting point to determine the Levelized Cost Of Electricity (LCOE) of a given technology.

By definition, the LCOE of the technology $z$, henceforth denoted by $P^{\mathrm{LC}, z}$, is that deterministic nonnegative real price of the electricity produced by the specific generation technology $z$, assumed constant over time, that makes the NPV equal to zero. The LCOE is hence a break-even reference unitary cost, i.e., the break-even cost per $\mathrm{MWh}$ of produced electricity ${ }^{2}$. To get the analytical form of $P^{\mathrm{LC}, z}$, let us pose

$$
E\left[P_{n}^{z}(\xi)\right]=(1+i)^{n-n_{b}} P^{\mathrm{LC}, z},
$$

where $i$ is the expected yearly inflation rate and $n_{b}$ labels the base year (which is used to transform real prices into nominal prices). By substituting Eq. (26) into Eq. (24) and equating $N P V^{z}$ to zero, we obtain

$$
P^{\mathrm{LC}, z}=\frac{\sum_{n=1}^{M} E\left[C_{n}^{z}(\xi)\right] F_{0, n}}{Q^{z} \sum_{n=1}^{M}(1+i)^{n-n_{b}} F_{0, n}}+\frac{I_{0}^{z}-T_{c} \sum_{n=1}^{M} D_{n}^{z} F_{0, n}}{\left(1-T_{c}\right) Q^{z} \sum_{n=1}^{M}(1+i)^{n-n_{b}} F_{0, n}} .
$$

In order to include into the analysis the risk due to random movements of revenues and costs, we must extend the classic NPV metrics. Now we are going to define the stochastic NPV. Such a definition must satisfy the constraint that the classic NPV must coincide with the mean of the stochastic NPV, i.e.,

$$
N P V^{z}=E\left[N P V^{z}(\xi)\right] .
$$

We hence define the stochastic NPV of the technology $z$ as the random variable

$$
\begin{aligned}
N P V^{z}(\xi)= & \left(1-T_{c}\right) Q^{z} \sum_{n=1}^{M} P_{n}^{z}(\xi) F_{0, n} \\
& -\left(1-T_{c}\right) \sum_{n=1}^{M} C_{n}^{z}(\xi) F_{0, n}+T_{c} \sum_{n=1}^{M} D_{n}^{z} F_{0, n}-I_{0}^{z} .
\end{aligned}
$$

\footnotetext{
${ }^{2}$ LCOE represents the generating costs at the plant level (busbar costs) and does not include transmission and distribution costs and all possible network infrastructures adjustments [22, 34].
} 
Starting from the definition of the stochastic NPV of the technology $z$, it is straightforward to introduce the stochastic LCOE of the technology $z$. Let us denote by $P^{\mathrm{LC}, z}(\xi)$ the stochastic LCOE of the technology $z . P^{\mathrm{LC}, z}(\xi)$ is defined path by path as that nonnegative real price of the electricity produced by the specific generation technology $z$, assumed constant over time, that makes the stochastic $N P V^{z}(\xi)$ equal to zero. To get the analytical form of the stochastic LCOE, let us pose

$$
P_{n}^{z}(\xi)=(1+i)^{n-n_{b}} P^{\mathrm{LC}, z}(\xi)
$$

thus obtaining from Eq. (29),

$$
\begin{aligned}
P^{\mathrm{LC}, z}(\xi)= & \frac{\sum_{n=1}^{M} C_{n}^{z}(\xi) F_{0, n}}{Q^{z} \sum_{n=1}^{M}(1+i)^{n-n_{b}} F_{0, n}} \\
& +\frac{I_{0}^{z}-T_{c} \sum_{n=1}^{M} D_{n}^{z} F_{0, n}}{\left(1-T_{c}\right) Q^{z} \sum_{n=1}^{M}(1+i)^{n-n_{b}} F_{0, n}} .
\end{aligned}
$$

As in the case of the stochastic NPV, Eq. (31) shows that the mean of the stochastic LCOE coincides with the classic, deterministic LCOE.

By substituting Eq. (31) into Eq. (29) we can obtain a very useful relationship between the stochastic NPV and the stochastic LCOE of the generation technology $z$, namely

$$
N P V^{z}(\xi)=\left(1-T_{c}\right) Q^{z} \sum_{n=1}^{M}\left[P_{n}^{z}(\xi)-P^{\mathrm{LC}, z}(\xi)(1+i)^{n-n_{b}}\right] F_{0, n}
$$

We remark that the relevant quantity for evaluating an investment in a generating technology is not the NPV itself (for which doubling the size of a plant would double the NPV), but the unitary NPV, i.e., the NPV per unit of generated electricity. We can, therefore, introduce a 'reduced stochastic NPV' in the following form,

$$
N P V_{\mathrm{red}}^{z}(\xi)=\frac{N P V^{z}(\xi)}{\left(1-T_{c}\right) Q^{z} \sum_{n=1}^{M}(1+i)^{n-n_{b}} F_{0, n}} .
$$

The reduced stochastic NPV can be cast in a much more expressive form. From Eq. (32) we namely get

$$
N P V_{\text {red }}^{z}(\xi)=\hat{P}^{z}(\xi)-P^{\mathrm{LC}, z}(\xi)
$$

where

$$
\hat{P}^{z}(\xi)=\frac{\sum_{n=1}^{M} P_{n}^{z}(\xi) F_{0, n}}{\sum_{n=1}^{M}(1+i)^{n-n_{b}} F_{0, n}} .
$$

Equation (34) clearly shows that break-even or profitability can be reached if and only if $E\left[\hat{P}^{z}(\xi)\right] \geq P^{\mathrm{LC}, z}$ (it means that the right quantity to be compared with the deterministic LCOE is $E\left[\hat{P}^{z}(\xi)\right]$ ). For dispatchable baseload technologies, such as 
nuclear, coal or combined-cycle gas turbines (CCGTs), which can have the same electricity output profile, $P_{n}^{z}$ is a technology independent quantity, i.e.,

$$
P_{n}^{z}(\xi)=P_{n}^{b}(\xi)
$$

where $P_{n}^{\mathrm{b}}$ denotes the (yearly averaged) unitary selling price of the baseload generation in the year $n$. In such a case, Eq. (34) becomes

$$
N P V_{\text {red }}^{z}(\xi)=\hat{P}^{\mathrm{b}}(\xi)-P^{\mathrm{LC}, z}(\xi)
$$

where

$$
\hat{P}^{\mathrm{b}}(\xi)=\frac{\sum_{n=1}^{M} P_{n}^{b}(\xi) F_{0, n}}{\sum_{n=1}^{M}(1+i)^{n-n_{b}} F_{0, n}} .
$$

Very often in the literature, the classic LCOE is used as a metric to compare generation costs of different technologies [9, 22]. That is, the classic LCOE metric has been used as an alternative to the classic NPV metric. For baseload generation, an economic comparison through LCOE makes sense because, as shown by Eq. (37), the technology that maximizes the expected reduced NPV is the technology that minimizes LCOE. This close link between the LCOE methodology and the financial notion of NPV 'has always heightened its appeal' [22]. This simple metric allows for a straightforward comparison of technologies that have different sizes, different lifetimes and different cost profiles in both regulated and liberalized electricity markets. However, in the case of Variable Renewable Energy (VRE) sources, such as wind or solar sources, $\hat{P}_{n}^{z}(\xi)$ can be a technology dependent parameter. Namely, in liberalized markets the hourly electricity output profile of non-dispatchable technologies can significantly differ between each other, and the LCOE evaluation approach should be carefully used for comparative purposes. Well aware of this, some Authors tried to investigate timing impact of electricity generation from VRE sources [23, 43]. In any case, being the LCOE a break-even reference unitary cost, it is a useful reference cost metric which can be compared with expected electricity market prices for checking, on the basis of Eq. (34), if break-even can be reached.

The next sections will be devoted to compute stochastic revenues and costs. Our aim ere his to provide a model to evaluate long-run investments in new generation technologies under uncertainty through the stochastic NPV metric. Without loss of generality, in the following we assume that the evaluation time, $n=0$, coincides with the base year, $n_{b}$.

\section{Modeling revenues}

When modeling revenues, we assumed that the dynamics of electricity prices is described by Model 3, the more realistic model that well reproduces most of the observed features of market prices. This model was calibrated on past data, in a backward looking way, separating the deterministic component of Eq. (2) from the 
Fig. 7 One-year autocorrelation of the detrended log-revenues process

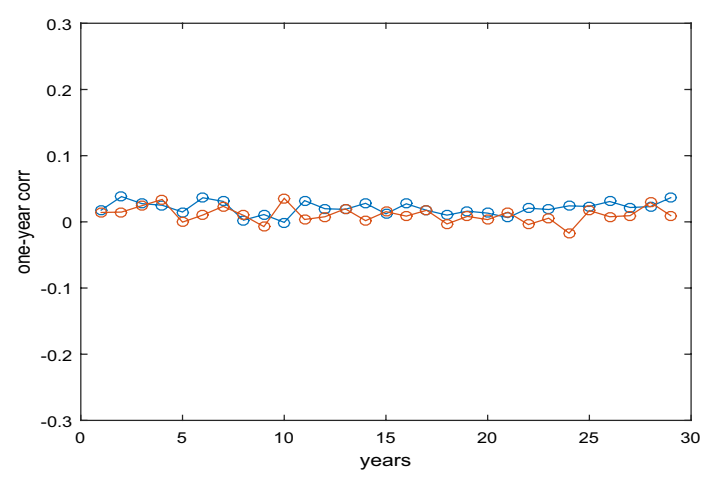

stochastic component. Since we now want to include macroeconomic forward looking information, we can replace in Eq. (2) the values of $b_{0}$ and $b_{1}$ related to the linear (affine) trend with new values that can account for macroeconomic views on the future long-term evolution of electricity prices. The $\beta_{0}$ and $\beta_{1}$ parameters will be determined in a such a way to match the expected long-run mean, the expected inflation rate, and the expected real escalation rate of power prices. Such macroeconomic estimates can be found in the Annual Energy Outlook 2019 [9] provided by the US Energy Information Administration.

According to both classic and stochastic NPV approaches the revenues from selling electricity during the annual time interval $[n-1, n]$ must be computed as a lump sum valued at time $n$. Limiting our analysis to baseload generation, the revenues term of Eq. (37) can be computed assuming that $P_{n}^{\mathrm{b}}$ is the annual averages of daily market prices, i.e.,

$$
P_{n}^{\mathrm{b}}=e^{\beta_{0}+\beta_{1} n}\left[\frac{1}{365} \sum_{k=1}^{365} P_{0}\left(t_{k n}\right)\right],
$$

where $\beta_{0}$ and $\beta_{1}$ account for a forward looking linear (affine) trend. Such parameters go to replace $b_{0}$ and $b_{1} . P_{0}\left(t_{k n}\right)$ denotes the electricity price at the $k$ th day of the $n$th year, computed with $b_{0}=b_{1}=0$. The dependence on the path $\xi$ will be henceforth omitted. To investigate the statistical properties of $P_{n}^{\mathrm{b}}$, let us consider the detrended log-revenues process, $h_{n}^{\mathrm{b}}$, given by

$$
h_{n}^{\mathrm{b}}=\log P_{n}^{\mathrm{b}}-\beta_{0}-\beta_{1} n .
$$

Figure 7 shows the time behavior of the 1-year autocorrelation of $h_{n}^{\mathrm{b}}$ as $n$ varies on a 30-year time horizon, computed using estimated parameters at Palo Verde and PJM markets. Figure 8 depicts the time behavior of the first four moments of the detrended log-revenues process as as $n$ varies on a 30-year time horizon.

We notice that the random variables $h_{n}^{\mathrm{b}}(n \geq 1)$ are uncorrelated random variables with same mean, $\bar{h}^{\mathrm{b}}$ (about 0.06 at Palo Verde, and 0.05 at PJM), same standard deviation, $\Sigma_{\mathrm{b}}$ (about $9.46 \%$ at Palo Verde, and $5.37 \%$ at PJM), zero skewness and kurtosis equal to three. Moreover, we performed some tests of normality, such as the Jarque-Bera test, the Kolmogorov-Smirnov test, the Anderson-Darling test and 

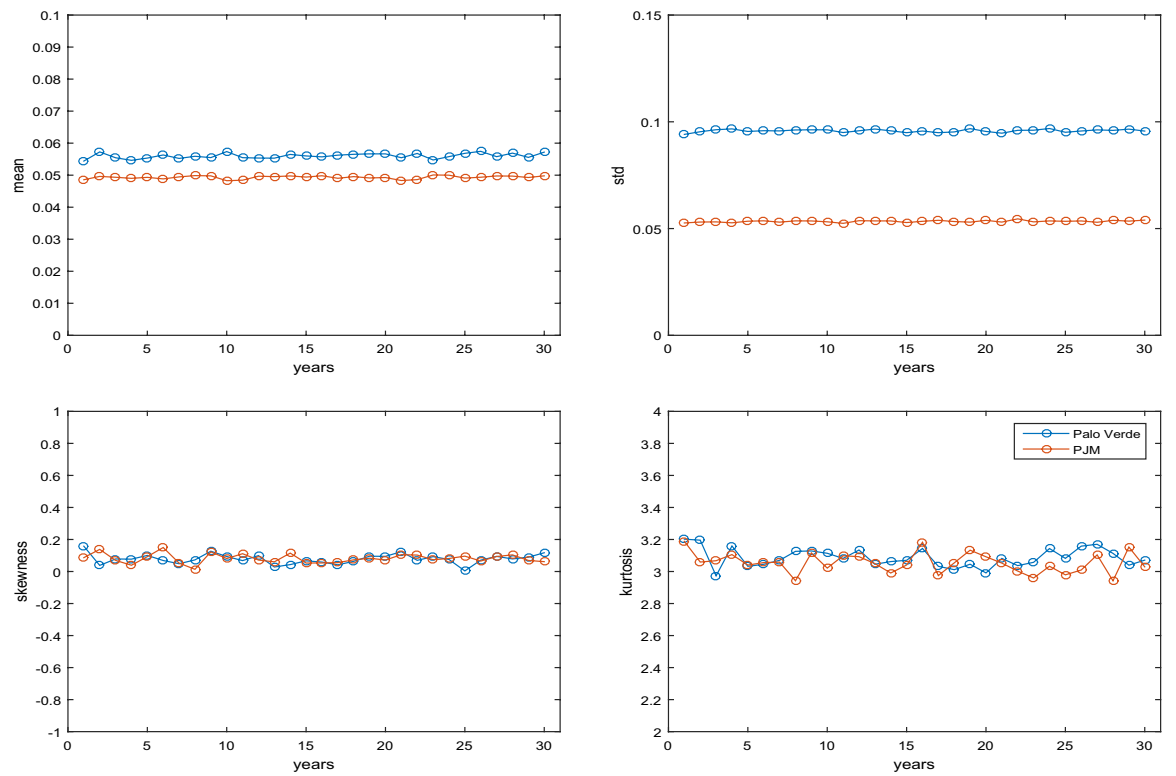

Fig. 8 Time behavior of the first four moments of the detrended log-revenues process

the chi-square test on Monte Carlo generated samples with sample size of five thousands trials. All these tests reveal that the hypothesis of normality for $h_{n}^{\mathrm{b}}(n \geq 1)$ cannot be rejected. As a consequence, we assume that $h_{n}^{\mathrm{b}}(n \geq 1)$ are i.i.d. normal random variable with mean $\bar{h}^{\mathrm{b}}$ and standard deviation $\Sigma_{\mathrm{b}}$, i.e., $h_{n}^{\mathrm{b}} \sim N\left(\bar{h}^{\mathrm{b}}, \Sigma_{\mathrm{b}}^{2}\right)$. This is an important result which is very useful to compute revenues from selling electricity on a long-term timescale.

Now we need to determine $\beta_{0}$ and $\beta_{1}$. This can be done using macroeconomic views about the long-run behavior of power prices. We thus require that

$$
\exp \left(\beta_{0}+\bar{h}^{\mathrm{b}}+\frac{1}{2} \Sigma_{\mathrm{b}}^{2}\right)=A^{\mathrm{b}}
$$

where $A^{\mathrm{b}}$ is the current annual average of the electricity generation price, and

$$
\beta_{1}=\pi+\pi^{\mathrm{b}},
$$

where $\pi=\ln (1+i)$ and $\pi^{\mathrm{b}}$ accounts for the view on the real escalation rate of power prices, i.e., $\pi^{\mathrm{b}}=\ln \left(1+k^{\mathrm{b}}\right)$ with $k^{\mathrm{b}}$ the expected real escalation rate of power prices. The Annual Energy Outlook 2019 [9] provides the following values, $A^{\mathrm{b}}=64 \$_{2018}$ per MWh, $i=2.3 \%$ per annum, and $k^{\mathrm{b}}=-0.5 \%$ per annum.

Finally, we point out that the above analysis could also have been carried out using Model 1 or Model 2, which are special cases of Model 3. However, the estimate of the log-revenues standard deviation parameter, $\Sigma_{\mathrm{b}}$, could be affected by errors due to a naive choice of the short-term model. In fact, Model 1 underestimates the log-revenues standard deviation (about 6.16\% at Palo Verde, and $4.79 \%$ at 

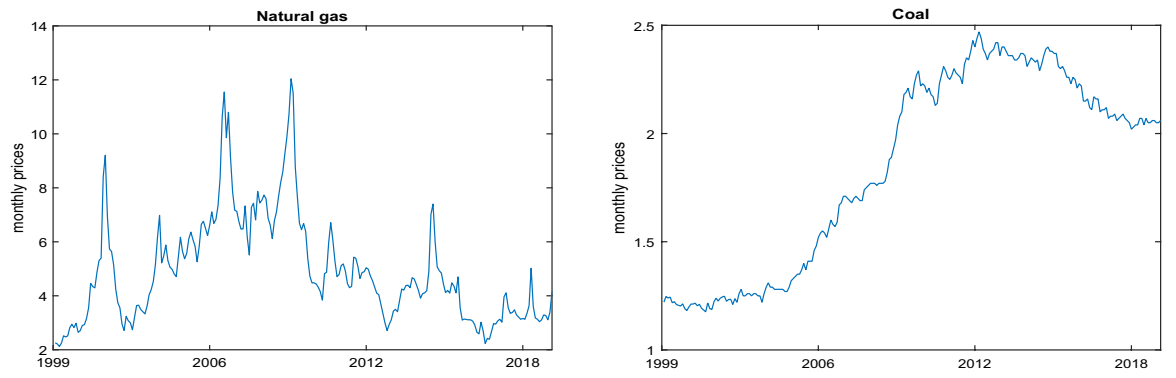

Fig. 9 Historical behavior of fossil fuel market prices since January, 1999-November, 2018. Left panel: natural gas. Right panel: coal

PJM) and, on the contrary, Model 2 overestimates such a parameter (about $10.93 \%$ at Palo Verde, and 5.94\% at PJM). Although these values differ slightly in the case of PJM, such differences become large in the case of Palo Verde, especially for Model 1. This fact has important consequences on the shape of the probabilistic distribution of the stochastic NPV leading to an incorrect assessment of the risk associated with the investment [28]. This would lead energy companies and policy makers to misjudge the risk associated with new investments in power generation. For these reasons, in the empirical analysis discussed in Sect. 7 we will use the standard deviation value estimated on Palo Verde market data using Model 3.

\section{Modeling fuel price dynamics}

To compute stochastic NPVs of new generating technologies we need to determine the stochastic behavior of fuel costs. In this section, we accurately model the stochastic dynamics of fuels and $\mathrm{CO}_{2}$ prices which are the main sources of risk when power generating costs are considered.

\subsection{Modeling fossil fuel prices}

Figure 9 shows the historical behavior of natural gas and coal prices. Our data set consists of time series of gas and coal prices at a monthly frequency since January, 1999 until November, 2018. Prices are expressed in nominal dollars per mmBtu, i.e., nominal dollars per million Btus. Data refer to the cost of natural gas and coal receipts at electric generating plants, and they were downloaded from the US Energy Information Administration at site www.eia.doe.gov/totalenergy/data.

Figure 10 shows the historical behavior of fossil fuel log-returns, calculated as monthly changes in the natural logarithm of monthly prices. Table 7 displays the descriptive statistics of fossil fuel log-returns.

The empirical analysis reveals that the time series of gas and coal log-returns do not show infra-annual seasonality and are almost uncorrelated (the correlation coefficient in the period under investigation is about -0.0052 ). 

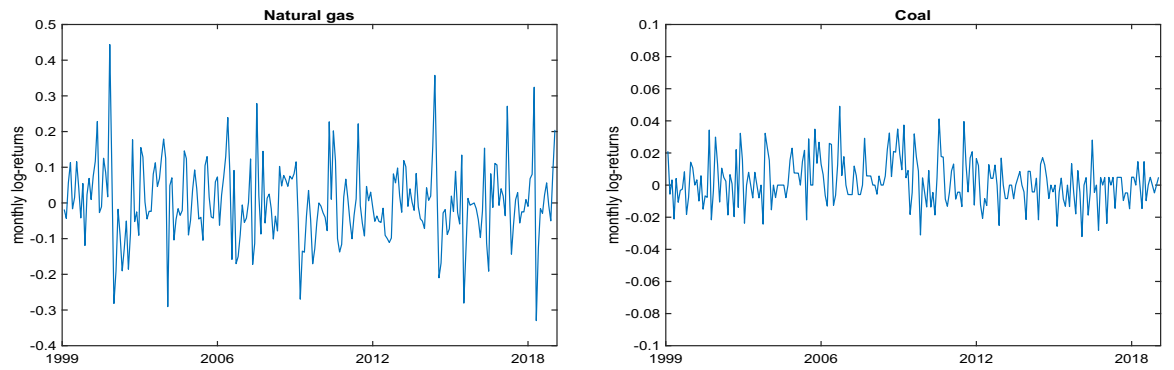

Fig. 10 Historical behavior of fossil fuel log-returns since January, 1999-November, 2018. Left panel: natural gas. Right panel: coal

Table 7 Descriptive statistics of fossil fuel log-returns

\begin{tabular}{lllll}
\hline & Mean & St. dev. & Skewness & Kurtosis \\
\hline Gas & 0.0026 & 0.1091 & 0.3132 & 4.6335 \\
Coal & 0.0022 & 0.0143 & 0.4007 & 3.3687 \\
\hline
\end{tabular}

Geometric Brownian Motion (GBM) is often used in the literature to model fossil fuel price dynamics [21, 33]. However, looking at Fig. 10, it seems that such process cannot be able to fully capture the observed dynamics of gas log-returns. Evidence exists for a more complicated behavior of gas prices showing mean-reversion, jumps and stochastic volatility [15]. We propose, therefore, a stochastic model, in which the time evolution of of gas prices is described by a mean-reverting jump-diffusion model. In contrast, to describe the dynamics of coal prices we use a GBM stochastic process. Observed coal prices, in fact, do not show mean-reversion patterns in the period under investigation, and the kurtosis value (3.3687) is consistent with normally distributed log-returns.

\subsubsection{Modeling natural gas price dynamics}

To model the gas price dynamics, let us denote by $P^{\mathrm{ga}}(t)$ the gas market price at time $t$ (the suffix 'ga' stands for 'gas'), expressed in nominal dollars per mmBtu, and by $s^{\mathrm{ga}}(t)=\ln P^{\mathrm{ga}}(t)$ its natural logarithm. We assume that $s^{\mathrm{ga}}(t)$ can be decomposed as follows,

$$
s^{\mathrm{ga}}(t)=b_{0}^{\mathrm{ga}}+x^{\mathrm{ga}}(t)
$$

where $b_{0}^{\mathrm{ga}}$ accounts for a constant trend and $x^{\mathrm{ga}}(t)$ for the stochastic component of the dynamics. In the period under investigation, the gas price dynamics does not show any linear trend and the empirical analysis confirms this feature. We estimated $b_{0}^{\mathrm{ga}}$ on market data using Ordinary Least Squares (OLS) techniques, thus finding $b_{0}^{\mathrm{ga}}=1.5224$. Looking at the left panel of Fig. 9, it is worth to observe that US natural gas market went through important transitions in the sample period. In the early 2000s, prices were trending upward as conventional US natural gas production was 
Table 8 Estimation results of the stochastic component of the gas price dynamics

\begin{tabular}{llll}
\hline$\alpha^{\mathrm{ga}}$ & $\sigma^{\mathrm{ga}}$ & $\lambda^{\mathrm{ga}}$ & $\sigma_{J}^{\mathrm{ga}}$ \\
\hline 0.0408 & 0.0789 & 0.2532 & 0.1447 \\
$(0.0095)$ & $(0.0083)$ & $(0.0426)$ & $(0.0159)$ \\
\hline
\end{tabular}

Standard errors are between parentheses

Standard deviations are between parentheses

\begin{tabular}{llll}
\hline Mean & St. dev. & Skewness & Kurtosis \\
\hline 0.0030 & 0.1086 & 0.0033 & 4.6346 \\
$(0.0016)$ & $(0.0070)$ & $(0.3376)$ & $(0.9208)$ \\
\hline
\end{tabular}

Table 9 Statistics of simulated paths log-returns using estimated parameters

declining over time, then the boom in unconventional gas production coincided with a persistent decrease in natural gas prices in the 2010s. Moreover, gas prices were trending upward again at the end of 2010s and macroeconomic projections to 2050 show a persistent upward trend in prices [9]. Over very long time horizons such trend changes can be considered as random events and we account for them in the stochastic component of the dynamics through a mean-reversion mechanism in a jump-diffusion process. We assume, therefore, that the time evolution of the stochastic component of the gas price dynamics, $x^{\mathrm{ga}}(t)$, is described by the following stochastic differential equation,

$$
d x^{\mathrm{ga}}(t)=-\alpha^{\mathrm{ga}} x^{\mathrm{ga}}(t) d t+\sigma^{\mathrm{ga}} d w^{\mathrm{ga}}(t)+J^{\mathrm{ga}} d q^{\mathrm{ga}}(t),
$$

where $w^{\mathrm{ga}}(t)$ is a Wiener process and $q^{\mathrm{ga}}(t)$ is a Poisson process with constant intensity $\lambda^{\text {ga }}$. The random jump amplitude $J^{\text {ga }}$ is distributed according to a normal random variable with zero mean and standard deviation $\sigma_{J}^{\text {ga }}$, i.e., $J \sim N\left(0,\left(\sigma_{J}^{\text {ga }}\right)^{2}\right)$. We assume that the Wiener process $w^{\text {ga }}$, the Poisson process $q^{\text {ga }}$, and the jump amplitude $J^{\mathrm{ga}}$ are mutually independent processes. The stochastic component of the dynamics was estimated on market data by maximum likelihood using the Euler discretization with time step $\Delta t$ equal to 1 month. Estimation results are depicted in Table 8.

The statistical analysis of simulated trajectories confirms that the jump-diffusion model offers an interesting agreement with market data. The first four moments of paths log-returns, obtained averaging over ten thousands paths randomly generated using estimated parameters, are displayed in Table 9.

In computing the stochastic NPV of gas generation, gas costs incurred in the annual time interval $[n-1, n]$ must be computed as a lump sum and valued at time $n$. We assume that such costs (per mmBtu) in the year $n$ are determined as a monthly market price average, $P_{n}^{\mathrm{ga}}$, given by

$$
P_{n}^{\mathrm{gaa}}=e^{\beta_{0}^{\mathrm{ga}}+\beta_{1}^{\mathrm{ga}} n}\left[\frac{1}{12} \sum_{k=1}^{12} P^{\mathrm{ga}}\left(t_{k n}\right)\right],
$$



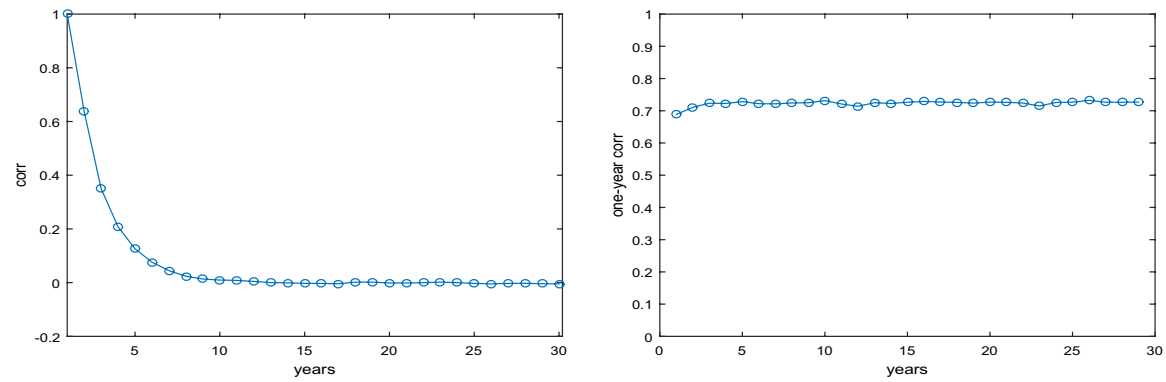

Fig. 11 The autocorrelation function of the detrended log-cost process (left panel), and the 1-year autocorrelation function (right panel)
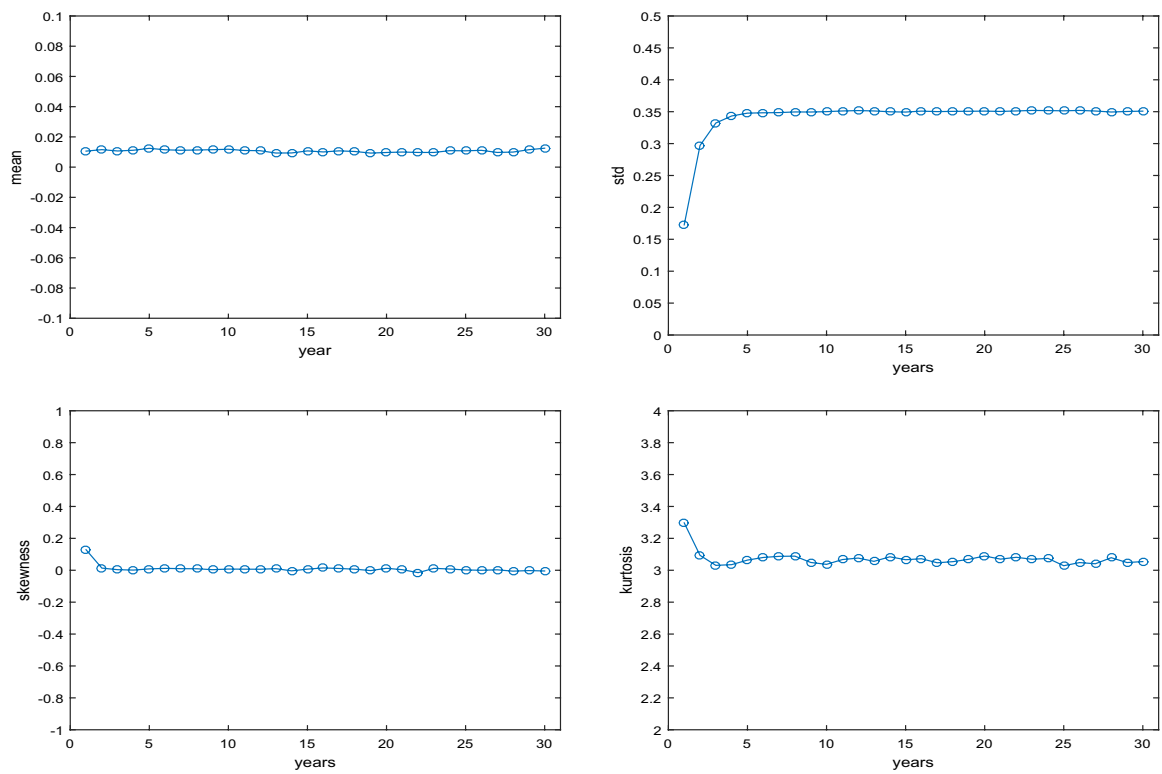

Fig. 12 Time behavior of the first four moments of the detrended log-cost process

where $\beta_{0}^{\mathrm{ga}}$ and $\beta_{1}^{\mathrm{ga}}$ account for a forward looking linear (affine) trend, and $t_{k n}$ denotes the $k$ th month of the $n$th year. The dependence on the path $\xi$ has been omitted. The parameters $\beta_{0}^{\mathrm{ga}}$ and $\beta_{1}^{\mathrm{ga}}$ allow us to calibrate the model on macroeconomic views about the future trend of gas market prices.

To investigate the statistical properties of $P_{n}^{\mathrm{ga}}$, let us consider the detrended log-cost process given by

$$
h_{n}^{\mathrm{ga}}=\log P_{n}^{\mathrm{ga}}-\beta_{0}^{\mathrm{ga}}-\beta_{1}^{\mathrm{ga}} n .
$$

Figure 11 shows the time behavior of the autocorrelation function (left panel) and the 1-year autocorrelation (right panel) of $h_{n}^{\mathrm{ga}}(n \geq 1)$ as $n$ varies on a 30-year time 
horizon, computed with estimated parameters. Figure 12 depicts the time behavior of the first four moments of $h_{n}^{\mathrm{ga}}$ as $n$ varies on a 30-year time horizon, computed with estimated parameters. We noticed that the random variables $h_{n}^{\mathrm{ga}}(n \geq 1)$ are correlated random variables with a constant correlation coefficient, which is approximately equal to 0.7 . After a transient period of about 3 year, such random variables are characterized by the same values of mean, $\bar{h}^{\text {ga }}$ (about 0.02 ), and the same value of the standard deviation, $\Sigma_{\text {ga }}$ (about 0.35), zero skewness and kurtosis equal to three. Moreover, we performed some tests of normality such as the Jarque-Bera test, the Kolmogorov-Smirnov test, the Anderson-Darling test and the chi-square test on Monte Carlo generated samples with sample size of five thousands trials. All these tests reveal that the hypothesis of normality for $h_{n}^{\mathrm{b}}(n \geq 1)$ cannot be rejected. We assume, therefore, that $h_{n}^{\text {ga }}(n \geq 1)$ are correlated i.d. normal random variable with mean $\bar{h}^{\mathrm{ga}}$ and standard deviation $\Sigma_{\text {ga }}$, i.e., $h_{n}^{\mathrm{ga}} \sim N\left(\bar{h}^{\mathrm{ga}}, \Sigma_{\mathrm{ga}}^{2}\right)$. This is a further important result, useful to compute gas costs on a long-term horizon.

The calibration of the model on macroeconomic views about long-term behavior of gas prices can proceed as in the electricity case. Namely, we require that

$$
\exp \left(\beta_{0}^{\mathrm{ga}}+\bar{h}^{\mathrm{ga}}+\frac{1}{2} \Sigma_{\mathrm{ga}}^{2}\right)=A^{\mathrm{ga}},
$$

where $A^{\text {ga }}$ is the current annual average of the gas price, and

$$
\beta_{1}^{\mathrm{ga}}=\pi+\pi^{\mathrm{ga}}
$$

where $\pi^{\text {ga }}$ accounts for the view on the real escalation rate of gas prices, i.e., $\pi^{\mathrm{ga}}=\ln \left(1+k^{\mathrm{ga}}\right)$ and $k^{\mathrm{ga}}$ is the expected real escalation rate of gas prices. The Annual Energy Outlook 2019 [9] provides the following values, $A^{\text {ga }}=3.54 \$_{2018}$ per $\mathrm{mmBtu}$, and $k^{\mathrm{ga}}=1.4 \%$ per annum. Such values are also reported in Table 10.

\subsubsection{Modeling coal price dynamics}

To model the coal price dynamics, let us denote by $P^{\mathrm{co}}(t)$ the coal market price at time $t$ (the suffix 'co' stands for 'coal'), expressed in nominal dollars per mmBtu. We assume that the dynamics of $P^{\mathrm{co}}(t)$ is described by a GBM process of the type,

$$
\frac{d P^{\mathrm{co}}(t)}{P^{\mathrm{co}}(t)}=\left(\pi^{\mathrm{co}}+\pi\right) d t+\sigma^{\mathrm{co}} d w^{\mathrm{co}}(t),
$$

where $w^{\text {co }}(t)$ is a Wiener process. The volatility parameter is set at the value 0.0143 on a monthly basis (see Table 7 ), i.e., $\sigma^{\text {co }}=0.05$ on an annual basis. The drift coefficient accounts for the expected inflation, $\pi$, and the expected real escalation rate of coal prices, $\pi^{\mathrm{co}}=\ln \left(1+k^{\mathrm{co}}\right)$, where $k^{\mathrm{co}}$ is the expected real escalation rate of coal prices. The Annual Energy Outlook 2019 [9] provides the value $k^{\text {co }}=0.2 \%$ per annum. Such value is also reported in Table 10. Since the correlation between coal market prices and power market prices is negligible [21], the Wiener process, $w^{\mathrm{co}}(t)$, is assumed to be independent from the stochastic processes driving the time evolution of power prices and gas prices. Differently from mean-reverting processes, 

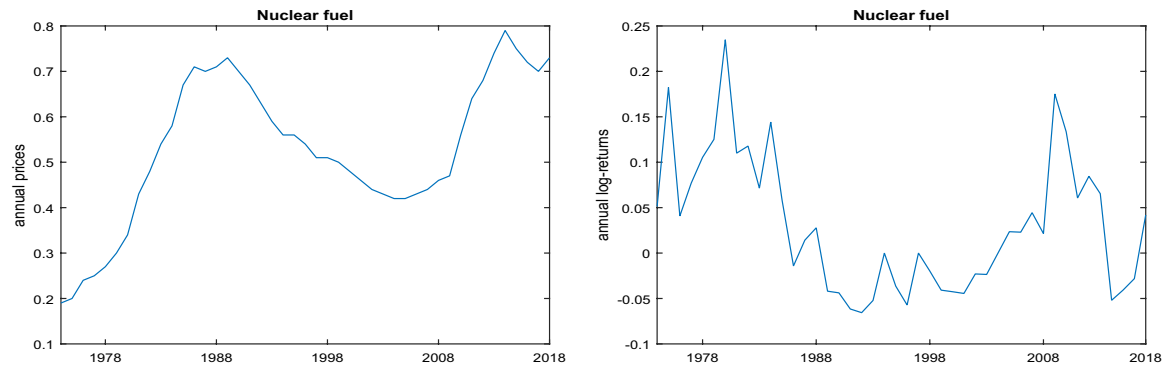

Fig. 13 Historical behavior of nuclear fuel prices (left panel) and log-returns (right panel) since 19732017

Table 10 Technical assumptions

\begin{tabular}{lllll}
\hline & Units & Gas & Coal & Nuclear \\
\hline Nominal capacity factor & & $87 \%$ & $85 \%$ & $90 \%$ \\
Heat rate & Btu/kWh & 6600 & 8800 & 10461 \\
Overnight cost & $\$ / \mathrm{kW}$ & 999 & 3747 & 6034 \\
Fixed O\&M costs & $\$ / \mathrm{kW} /$ year & 11.33 & 43.37 & 103.31 \\
Variable O\&M costs & mill \$/kWh & 3.61 & 4.74 & 2.37 \\
Fuel costs & $\$ / \mathrm{mmBtu}$ & 3.54 & 2.11 & 0.75 \\
Fuel real escalation rate & & $1.4 \%$ & $0.2 \%$ & $0.2 \%$ \\
Decommissioning & $\$ / \mathrm{kW}$ & 50 & 200 & 1000 \\
CO ${ }_{2}$ intensity & Kg-C/mmBtu & 14.5 & 25.5 & 0 \\
Construction period & \# of years & 3 & 4 & 6 \\
Plant life & \# of years & $30-40$ & $30-40$ & $30-40-60$ \\
Depreciation scheme & & MACRS,20 & MACRS,20 & MACRS,20 \\
\hline
\end{tabular}

'mill' stands for 1/1000. Depreciation is developed according to the MACRS (Modified Accelerated Cost Recovery System) scheme

Geometric Brownian Motion has not stationary solutions for the probability density function. Then, the coal cost evaluation in computing the stochastic NPV of coal plants is performed pointwise at the end of each year using Equation (49) with an initial condition given by the coal price value reported in Table 10.

\subsection{Modeling nuclear fuel prices}

Our data set consists of a time series of nuclear fuel prices at an annual frequency since 1973 until 2017. Data can be downloaded from the US Energy Information Administration at site www.eia.doe.gov/opendata. Figure 13 shows the historical behavior of nuclear fuel prices (left panel) and their annual log-returns, calculated as annual changes in the natural logarithm of prices (right panel). Prices are expressed in nominal dollars per mmBtu. 
Let us denote by $P^{\text {nu }}(t)$ the nuclear fuel price at time $t$ (the suffix 'nu' stands for 'nuclear'). In the period under investigation log-returns do not show mean-reversion, and we assume that the dynamics of nuclear fuel prices is described by a GBM process of the type

$$
\frac{d P^{\mathrm{nu}}(t)}{P^{\mathrm{nu}}(t)}=\left(\pi^{\mathrm{nu}}+\pi\right) d t+\sigma^{\mathrm{nu}} d w^{\mathrm{nu}}(t)
$$

where $w^{\mathrm{nu}}(t)$ is a Wiener process and $\pi^{\mathrm{nu}}=\ln \left(1+k^{\mathrm{nu}}\right)$, being $k^{\mathrm{nu}}$ the expected real escalation rate of nuclear fuel prices. The Annual Energy Outlook 2019 [9] provides the following value $k^{\text {nu }}=0.2 \%$ per annum, as reported in Table 10 . The Wiener process, $w^{\mathrm{nu}}(t)$, is assumed to be independent from the stochastic processes driving the time evolution of power prices and fossil fuel prices.

The volatility parameter was estimated by maximum likelihood on the nuclear fuel dataset. We obtained the value $\sigma^{\text {nu }}=0.07$ on an annual basis. As in the coal case, the nuclear fuel cost evaluation for computing the stochastic NPV of nuclear power plants is performed pointwise at the end of each year using Eq. (50) with an initial condition given by the nuclear fuel price value reported in Table 10.

\subsection{Modeling $\mathrm{CO}_{2}$ prices}

Let us denote by $P^{\mathrm{ca}}(t)$ the $\mathrm{CO}_{2}$ price at time $t$ (the suffix 'ca' stands for 'carbon'), expressed in nominal dollars per ton of $\mathrm{CO}_{2}$. The dynamics of $\mathrm{CO}_{2}$ prices, is modeled according to a GBM process of the type

$$
\frac{d P^{\mathrm{ca}}(t)}{P^{\mathrm{ca}}(t)}=\pi d t+\sigma^{\mathrm{ca}} d w^{\mathrm{ca}}(t)
$$

where $\sigma^{\text {ca }}$ is the carbon volatility and $w^{\text {ca }}(t)$ is a Wiener process which is assumed to be independent from the stochastic processes driving the time evolution of power prices, fossil fuel prices, and nuclear fuel prices. However, the model can be extended to account for a possible correlation between $\mathrm{CO}_{2}$ prices and power prices. $\mathrm{A} \mathrm{CO}_{2}$ price equal to $30 \$_{2018}$ per ton of $\mathrm{CO}_{2}[7,22]$ is assumed as initial condition of the $\mathrm{CO}_{2}$ price process. Regarding the volatility, we consider a $\mathrm{CO}_{2}$ price volatility $\sigma^{\mathrm{ca}}=20 \%$. These assumptions try to depict a realistic scenario in order to investigate the impact of $\mathrm{CO}_{2}$ volatility on the risk of investments in fossil fuel power plants [14]. The contribution of $\mathrm{CO}_{2}$ costs to the stochastic NPV is computed pointwise at the end of each year.

\section{The stochastic NPV of generating electricity}

Table 10 details technical data and costs used in the empirical analysis. The main data source is the 'Annual Energy Outlook 2019' [9]. In particular, the cost of new generating technologies are taken from 'Capital Cost Estimates for Utility Scale Electricity Generating Plants' [12] and 'Cost and Performance Characteristics of New Generating Technologies, Annual Energy Outlook 2019-January 

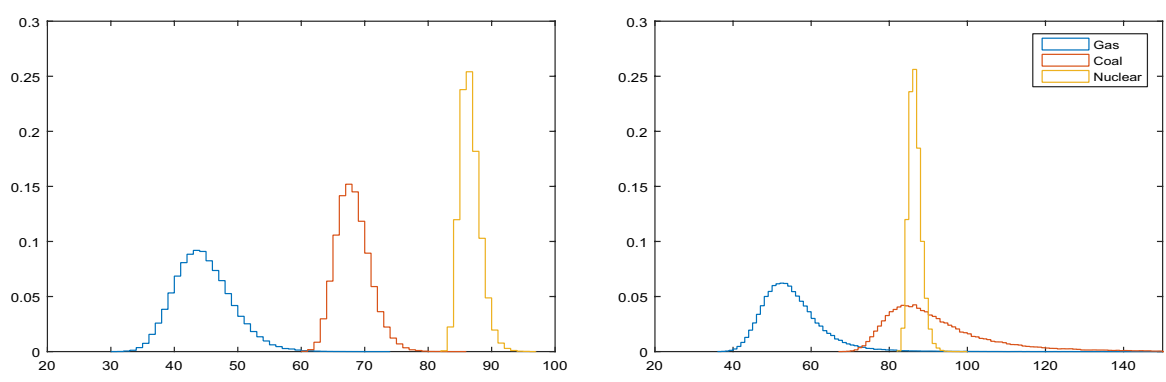

Fig. 14 Stochastic LCOE distributions without $\mathrm{CO}_{2}$ costs (left panel) and with $\mathrm{CO}_{2}$ costs (right panel) computed over a 30-year plant lifetime

2019' [10], both provided by the US Energy Information Administration. Data refer to a Conventional Natural Gas Combined Cycle (NGCC) facility for the gas technology, to an Ultra Supercritical Coal (USC) facility for the coal technology, and to an advanced PWR (Pressurized Water Reactor) nuclear power facility. All costs are denominated in year 2018 US dollars $\left(\$_{2018}\right)$. With the exception of the nuclear technology, decommissioning costs were set at about $5 \%$ of the overnight cost $[22,42]$. For nuclear power plants we assumed a larger percentage of the overnight cost to account for decommissioning and radioactive waste disposal $[39,51]$. Overnight costs are uniformly distributed on the construction period. In accordance to the Annual Energy Outlook 2019 (AEO 2019), we assumed an expected inflation rate $i=2.3 \%$ per annum, and a corporate tax rate $T_{c}=21 \%$ as specified in the Tax Cuts and Jobs Act of 2017. As in AEO 2019, all LCOE calculations are performed using a nominal after-tax WACC rate of $7.0 \%$ per annum $[9,11]$.

Probabilistic distributions of stochastic LCOE and reduced NPV [equation (hereinafter NPV)] of new generating technologies can be obtained by using Monte Carlo techniques. Random paths for electricity prices, fuel prices, and $\mathrm{CO}_{2}$ prices are generated according to dynamic models illustrated in the previous section. Along such paths, LCOE and NPV values are computed by using LCOE and NPV formulas reported in Sect. 4. Numerical computations are performed without and with $\mathrm{CO}_{2}$ stochastic costs. In this last case, we assumed that macroeconomic views on the future evolution of power prices as well as their volatility are not influenced by the inclusion of carbon costs. Computations are performed under the hypothesis of zero correlation between (unitary) revenues and costs. This is not a strong assumption, even in the case of gas fired plants. The empirical analysis developed in the previous sections revealed that annual revenues are not correlated over time. On the other side, gas generation annual costs show a high positive correlation over time. This implies that, although gas and power prices could show some cointegration relationship [36], nevertheless the correlation between annual revenues and costs, if there is any, must be negligible. However, the model can be extended in a straightforward way to include such a correlation.

Figure 14 depicts simulated distributions of the stochastic LCOE (without and with $\mathrm{CO}_{2}$ costs) of baseload sources computed on a 30-year plant lifetime. 

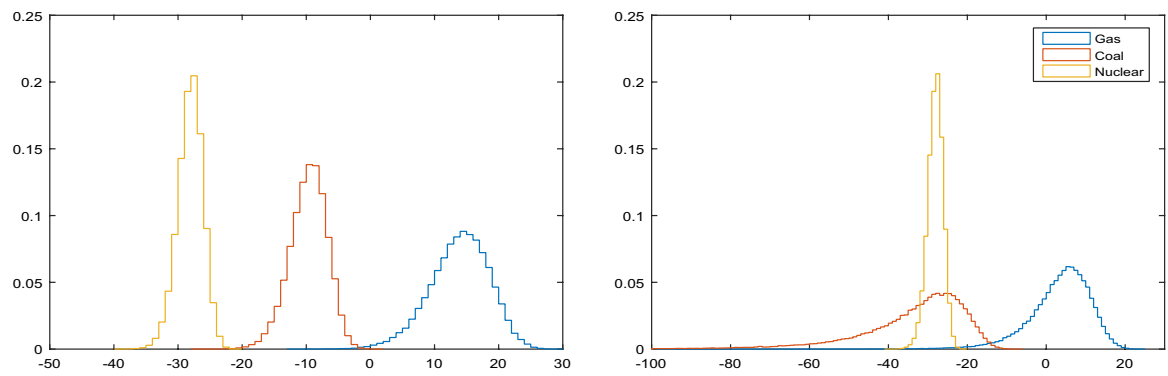

Fig. 15 Stochastic NPV distributions without $\mathrm{CO}_{2}$ costs (left panel) and with $\mathrm{CO}_{2}$ costs (right panel) computed over a 30 -year plant lifetime

Table 11 Expected LCOE values

\begin{tabular}{llll}
\hline & Gas & Coal & Nuclear \\
\hline 30-year & 42.6 & 68.0 & 86.5 \\
40-year & 42.6 & 63.6 & 78.8 \\
60-year & - & - & 72.4 \\
\hline
\end{tabular}

Table 12 Expected NPV values

\begin{tabular}{llll}
\hline & Gas & Coal & Nuclear \\
\hline 30-year & 17.4 & -8.0 & -26.5 \\
40-year & 16.6 & -4.4 & -19.6 \\
60 -year & - & - & -14.1 \\
\hline
\end{tabular}

Table 13 Statistics of stochastic NPV distributions of gas generation without $\mathrm{CO}_{2}$ costs (first row) and with $\mathrm{CO}_{2}$ costs (second row)

\begin{tabular}{lll}
\hline Mean & St. dev. & $p(N P V<0)$ \\
\hline 17.4 & 4.3 & $0.1 \%$ \\
6.8 & 7.9 & $15 \%$ \\
\hline
\end{tabular}

A 30-year plant lifetime is considered

Figure 15 depicts simulated distributions of the stochastic NPV of baseload sources (without and with $\mathrm{CO}_{2}$ costs) computed on a 30-year plant lifetime.

Table 11 reports LCOE values for power generation from natural gas, coal, and nuclear sources, computed (without $\mathrm{CO}_{2}$ costs) over different plant lifetimes. Table 12 reports expected NPV values for power generation from natural gas, coal, and nuclear sources, computed (without $\mathrm{CO}_{2}$ costs) over different plant lifetimes. All these distributions include forward looking views. With the exception of the gas technology, both coal and nuclear power generation show a negative expected NPV. Lengthening the plant lifetime does not modify this picture. 
The inclusion of $\mathrm{CO}_{2}$ costs into the analysis worses the picture. However, in the case of a carbon cost of $30 \$_{2018}$ per ton of $\mathrm{CO}_{2}$, and a volatility $\sigma^{\text {ca }}=20 \%$, the NPV of gas generation is still positive (about 6.8) even if the probability to get negative NPV is sensibly increased. Table 13 displays some statistics of stochastic NPV distributions for gas generation. Stochastic $\mathrm{CO}_{2}$ costs reduce the expected NPV and increase the standard deviation of the stochastic NPV distribution. As a consequence, the probability to get negative NPV strongly increases (from 0.1 to $15 \%$ when stochastic $\mathrm{CO}_{2}$ costs are included). This can be an alert ring for the profitability of the investment.

\section{Concluding remarks}

In this paper we provided a general methodology for valuing long-term investments in the power sector. In particular, investments in new generating technologies (fossil fuel and nuclear technologies) were analyzed and discussed. Stationary distributions of electricity and natural gas prices were used to determine long-term probabilistic distributions of revenues and costs on the whole lifetime of the plants. This approach can be useful for power planning decision making of energy companies and policy makers. By providing the probability density of stochastic NPVs, the proposed methodology allows the management to perform risk analysis of investments in capacity expansion by computing, for example, the Value at Risk (VaR) of a given investment, or the probability to obtain negative NPVs, which is in our opinion an important planning tool. Although our analysis was limited to baseload generation, it can be extended to peak-load generation and to VRE generating technologies in a straightforward way. In such cases, the proposed methodology allows us to include also uncertainty over capacity utilization. This will be the first direction of our future research.

We showed in the paper that, although the gas power generation seems to be the only viable option, nevertheless it is a very risky one [26]. The gas prices volatility is in fact very high and may cause large fluctuations around the expected NPV. In the presence of $\mathrm{CO}_{2}$ costs, the probability to get a negative value of the stochastic NPV of a gas fired plant is about $15 \%$. Risk reducing strategies through diversification of generating assets can be a very important solution. This was in fact the main reason for introducing stochastic NPV and stochastic LCOE. Electricity companies often own not just one among many dispatchable and non-dispatchable generation technologies, but mixtures of them, i.e., power generating portfolios. The approach proposed in this paper can be used to investigate the selection problem for power portfolios under uncertainty. In this regard, the stochastic NPV metrics as well as the stochastic LCOE metrics offer the possibility to perform portfolio risk analysis under general deviation measures, such as e.g., standard deviation and Conditional VaR Deviation (CVaRD) [25, 44]. Strategies that aim at reducing risk through diversification, in fact, allow one to investigate the trade-off between the expected NPV and risk, as measured by the standard deviation or by the CVaRD of the stochastic NPV. In this way, the management becomes able to define optimal generating portfolios. Although portfolio selection under uncertainty based on stochastic LCOE 
was developed in the literature [27, 28] also in the presence of VRE sources [29], the portfolio selection problem based on stochastic NPV with accurate modeling of electricity and fuel price dynamics has not yet been developed. This will be the second direction of our future research.

\section{Appendix: The time evolution of central moments in the jump-diffusion model}

In this appendix, we provide a formal derivation of central moments time evolution of the jump-diffusion stochastic process described by the following stochastic differential equation

$$
d x(t)=-\alpha x(t) d t+\sigma d w(t)+J d q(t),
$$

where the jump amplitude $J$ is an arbitrary random variable. The only assumption we make is that the Wiener process, $w(t)$, the Poisson process, $q(t)$, and the jump amplitude, $J$, are mutually independent processes.

Let us consider the zero-mean process,

$$
y(t)=x(t)-\mu(t),
$$

where $\mu(t)=E[x(t)]$. A closed form solution can be found for $\mu(t)$ and reads

$$
\mu(t)=x_{0} e^{-\alpha t}+\frac{\lambda E[J]}{\alpha}\left(1-e^{-\alpha t}\right),
$$

where $x_{0}$ is the initial condition of the dynamics, i.e., $x(0)=x_{0}$. The zero-mean process $y(t)$ satisfies the following jump-diffusion stochastic differential equation,

$$
d y(t)=-[\alpha y(t)+\lambda E[J]] d t+\sigma d w(t)+J d q(t) .
$$

Since the $n$-th central moment, $M_{n}$, is defined by

$$
M_{n}(t)=E\left[y(t)^{n}\right],
$$

the time evolution of $M_{n}(t)$ can be obtained by applying Itô's Lemma to the process $F(y)=y^{n}$, thus getting

$$
\begin{aligned}
M_{n}^{\prime}(t)= & -n \alpha M_{n}(t)-n \lambda E[J] M_{n-1}(t)+\frac{n(n-1)}{2} \sigma^{2} M_{n-2}(t) \\
& +\lambda \sum_{k=1}^{n}\left(\begin{array}{l}
n \\
k
\end{array}\right) M_{n-k}(t) E\left[J^{k}\right]
\end{aligned}
$$

for $n \geq 2$, being by definition $M_{0}(t)=1$ and $M_{1}(t)=0$. Exact solutions for the first central moments can be easily computed, and read 


$$
\begin{gathered}
M_{2}(t)=\frac{\sigma^{2}+\lambda E\left[J^{2}\right]}{2 \alpha}\left(1-e^{-2 \alpha t}\right), \\
M_{3}(t)=\frac{\lambda E\left[J^{3}\right]}{3 \alpha}\left(1-e^{-3 \alpha t}\right), \\
M_{4}(t)=\frac{\lambda E\left[J^{4}\right]}{4 \alpha}\left(1-e^{-4 \alpha t}\right)+3 M_{2}(t)^{2} .
\end{gathered}
$$

In the limit $t \rightarrow+\infty$, they tend to their stationary values,

$$
\begin{gathered}
M_{2}=\frac{\sigma^{2}+\lambda E\left[J^{2}\right]}{2 \alpha}, \\
M_{3}=\frac{\lambda E\left[J^{3}\right]}{3 \alpha}, \\
M_{4}=\frac{\lambda E\left[J^{4}\right]}{4 \alpha}+3 M_{2}^{2} .
\end{gathered}
$$

Higher order moments stationary values can be computed according to

$$
M_{n}=\frac{n-1}{2 \alpha} \sigma^{2} M_{n-2}+\frac{\lambda}{n \alpha} \sum_{k=2}^{n}\left(\begin{array}{l}
n \\
k
\end{array}\right) M_{n-k} E\left[J^{k}\right],
$$

for $n \geq 2$, being $M_{0}=1$ and $M_{1}=0$. Finally, we notice that the autocorrelation function,

$$
H(s, t)=\operatorname{Cov}(x(s), x(t)) \quad t \geq s,
$$

can be computed in a closed form. In fact, the time evolution of $H$ can be derived from Eq. (55) thus getting

$$
H^{\prime}(s, t)=-\alpha H(s, t) .
$$

Solving Eq. (66) under the initial condition $H(s, s)=M_{2}(s)$, we obtain

$$
\operatorname{Cov}(x(s), x(t))=\frac{\sigma^{2}+\lambda E\left[J^{2}\right]}{2 \alpha}\left[e^{-\alpha(s-t)}-e^{-\alpha(s+t)}\right] .
$$

Formulas reported in Sect. 3 and referred to Model 1 can be obtained in the particular case $J=0$. Formulas referred to Model 2 can be obtained in the case $J \sim N\left(0, \sigma_{J}^{2}\right)$. In this last case, we recall that 


$$
E\left[J^{2 k}\right]=\frac{(2 k) !}{2^{k} k !} \sigma^{2 k}
$$

Acknowledgements I would like to thank Carlo Lucheroni for fruitful discussion and an anonymous referee for useful comments.

Funding Open Access funding provided by Università degli Studi G. D’Annunzio Chieti Pescara.

Open Access This article is licensed under a Creative Commons Attribution 4.0 International License, which permits use, sharing, adaptation, distribution and reproduction in any medium or format, as long as you give appropriate credit to the original author(s) and the source, provide a link to the Creative Commons licence, and indicate if changes were made. The images or other third party material in this article are included in the article's Creative Commons licence, unless indicated otherwise in a credit line to the material. If material is not included in the article's Creative Commons licence and your intended use is not permitted by statutory regulation or exceeds the permitted use, you will need to obtain permission directly from the copyright holder. To view a copy of this licence, visit http://creativecommons.org/licen ses/by/4.0/.

\section{References}

1. Alonso, A.M., García-Martos, C., Rodríguez, J., Sánchez, M.J.: Seasonal dynamic factor analysis and bootstrap inference: application to electricity market forecasting. Technometrics 53(2), 137-151 (2011)

2. Bello, A., Bunn, D., Reneses, J., Muñoz, A.: Parametric density recalibration of a fundamental market model to forecast electricity prices. Energies 9, 20 (2016)

3. Bello, A., Bunn, D.W., Reneses, J., Muñoz, A.: Medium-term probabilistic forecasting of electricity prices: a hybrid approach. IEEE Trans. Power Syst. 32(1), 334-343 (2017)

4. Chen, H.: Power Grid Operation in a Market Environment: Economic Efficiency and Risk Mitigation. Wiley-IEEE Press, New York (2017)

5. Clements, A.E., Hurn, A.S., Li, Z.: Strategic bidding and rebidding in electricity markets. Energy Econ. 59, 24-36 (2016)

6. Cramton, P., Stoft, S.: A capacity market that makes sense. Electr. J. 18, $43-54$ (2005)

7. Du, Y., Parsons, J.E.: Update on the cost of nuclear power. MIT Working Paper (2009)

8. De Vries, L., Heijnen, P.: The impact of electricity market design upon investment under uncertainty: the effectiveness of capacity mechanisms. Util. Policy 16, 215-227 (2008)

9. EIA: Annual Energy Outlook 2019. U.S. Energy Information Administration, Department of Energy (2019)

10. EIA: Cost and Performance Characteristics of New Generating Technologies, Annual Energy Outlook 2019. U.S. Energy Information Administration, Department of Energy (2019)

11. EIA: Levelized cost and levelized avoided cost of new generation resources in the Annual Energy Outlook 2019. U.S. Energy Information Administration, Department of Energy (2019)

12. EIA: Capital cost estimates for utility scale electricity generating plants. U.S. Energy Information Administration, Department of Energy (2016)

13. Eydeland, A., Wolyniec, K.: Energy and Power Risk Management. Wiley, Chichester (2003)

14. Feng, Z.H., Zou, L.L., Wei, Y.M.: Carbon price volatility: evidence from EU ETS. Appl. Energy 88, 590-598 (2011)

15. García-Martos, C., Rodríguez, J., Sánchez, M.J.: Modelling and forecasting fossil fuels, $\mathrm{CO}_{2}$ and electricity and their volatilities. Appl. Energy 101, 363-375 (2013)

16. Gardiner, C.W.: Handbook of Stochastic Methods. Springer, Berlin (2004)

17. Hamilton, J.D.: A new approach to the economic analysis of nonstationary time series and the business cycle. Econometrica 57, 357-384 (1989)

18. Hamilton, J.D.: Time Series Analysis. Princeton University Press, Princeton (1994)

19. Hamm, G., Borison, A.: Forecasting long-run electricity prices. Electr. J. 19(7), 47-57 (2006)

20. Hanson, D., Schmalzer, D., Nichols, C., Balash, P.: The impacts of meeting a tight $\mathrm{CO}_{2}$ performance standard on the electric power sector. Energy Econ. 60, 476-485 (2016)

21. Hogue, M.T.: A review of the costs of nuclear power generation. BEBR, University of Utah (2012) 
22. IEA-NEA: Projected Costs of Generating Electricity. International Energy Agency - Nuclear Energy Association, OECD, Paris, France (2015)

23. Joskow, P.L.: Comparing the costs of intermittent and dispatchable electricity generating technologies. Am. Econ. Rev. 101, 238-241 (2011)

24. Kagiannas, A.G., Askounis, D.T., Psarras, J.: Power generation planning: a survey from monopoly to competition. Electr. Power Energy Syst. 26, 413-421 (2004)

25. Krokhml, P., Palmquist, J., Uryasev, S.: Portfolio optimization with conditional value-at-risk: objective and constraints. J. Risk 4, 3-68 (2002)

26. Larson, A.: The future looks bright for natural gas-fired power generation but price volatility is a wild card. Power 161, 20 (2017)

27. Lucheroni, C., Mari, C.: $\mathrm{CO}_{2}$ volatility impact on energy portfolio choice: a fully stochastic LCOE theory analysis. Appl. Energy 190, 278-290 (2017)

28. Lucheroni, C., Mari, C.: Risk shaping of optimal electricity portfolios in the stochastic LCOE theory. Comput. Oper. Res. 96, 374-385 (2018)

29. Lucheroni, C., Mari, C.: Optimal integration of intermittent renewables: a system LCOE stochastic approach. Energies 11, 20 (2018)

30. Lucia, J., Schwartz, E.S.: Electricity prices and power derivatives: evidence from the Nordic power exchange. Rev. Deriv. Res. 5, 5-50 (2002)

31. Madureira, N.L.: Key Concepts in Energy. Springer, Berlin (2014)

32. Mari, C.: Regime-switching characterization of electricity prices dynamics. Phys. A 371, 552-564 (2006)

33. Mari, C.: Hedging electricity price volatility using nuclear power. Appl. Energy 113, 615-621 (2014)

34. MIT: The future of nuclear power. Cambridge, United States (2003)

35. MIT: Update of the MIT 2003 - the future of nuclear power. Cambridge, United States (2009)

36. Mjelde, J.W., Bessler, D.A.: Market integration among electricity markets and their major fuel source markets. Energy Econ. 31, 482-491 (2009)

37. Mount, T.D., Ning, Y., Cai, X.: Predicting prices spikes in electricity markets using a regime-switching model with time-varying parameters. Energy Econ. 28, 62-80 (2006)

38. Nanduri, V., Kazemzadeh, N.: A Survey of Carbon Market Mechanisms and Models. Handbook of $\mathrm{CO}_{2}$ in Power Systems. Springer, Berlin (2012)

39. NEA: Costs of Decommissioning Nuclear Power Plants. Nuclear Energy Association. OECD, Paris (2016)

40. Nowotarski, J., Weron, R.: Recent advances in electricity price forecasting: a review of probabilistic forecasting. Renew. Sustain. Energy Rev. 20, 20 (2017)

41. Oliveira, F.S., Costa, M.L.G.: Capacity expansion under uncertainty in an oligopoly using indirect reinforcement-learning. Eur. J. Oper. Res. 267(3), 1039-1050 (2018)

42. Raimi, D.: Decommissioning US power plants: Decisions, costs, and key issues. Research For the Future (RFF) Report (2017)

43. Reichelstein, S., Sahoo, A.: Time of day pricing and the levelized cost of intermittent power generation. Energy Econ. 48, 97-108 (2015)

44. Rockafellar, R.T., Uryasev, S., Zabarankin, M.: Optimality conditions in portfolio analysis with general deviation measures. Math. Program. 20, 20 (2006)

45. Roques, F.A., Newbery, D.M., Nuttall, W.J., William, J.: Fuel mix diversification incentives in liberalized electricity markets: a mean-variance portfolio theory approach. Energy Econ. 30, 1831-1849 (2008)

46. Ross, S.A., Westerfield, R.W., Jaffe, J.: Corporate Finance. McGraw-Hill, New York (2010)

47. Sisodia, G.S., Soares, I., Banerji, S., Van den Poel, D.: The status of energy price modelling and its relevance to marketing in emerging economies. Energy Proced. 79, 500-505 (2015)

48. Weron, R., Bierbrauer, M., Trück, S.: Modeling electricity prices: jump-diffusion and regime switching. Phys. A 336, 39-48 (2004)

49. Weron, R.: Electricity price forecasting: a review of the state-of-the-art with a look into the future. Int. J. Forecast. 30(4), 1030-1081 (2014)

50. Weron, R.: Modeling and Forecasting Electricity Loads and Prices: A Statistical Approach. Wiley, New York (2013)

51. WNA: Economics of Nuclear Power. World Nuclear Association, London (2018)

52. Zhan, Y., Zheng, Q.P., Wang, J., Pinson, P.: Generation expansion planning with large amounts of wind power via decision-dependent stochastic programming. IEEE Trans. Power Syst. 32(4), 3015-3026 (2017) 
53. Zhang, J., Tan, Z., Yang, S.: Day-ahead electricity price forecasting by a new hybrid method. Comput. Ind. Eng. 63(3), 695-701 (2012)

54. Ziel, F., Steinert, R.: Probabilistic mid- and long-term electricity price forecasting. Technical Report (2018)

Publisher's Note Springer Nature remains neutral with regard to jurisdictional claims in published maps and institutional affiliations. 